\title{
Improved Procedures for the Syntheses of Pyrido- and Pyrrolo[2,3- $d]$ pyrimidines, and Ribosides Thereof
}

\author{
Tsuneo Itoh, ${ }^{* a}$ Raphael G. MeliK-Ohanjanian, ${ }^{1)}$ Ichiro IshiKawa, ${ }^{a}$ Norio Kawahara, ${ }^{b}$ Yoshihisa Mizuno, ${ }^{a}$ Yoshio
} Honma, ${ }^{c}$ Motoo Hozumi, ${ }^{c}$ and Haruo OGura ${ }^{a}$

School of Pharmaceutical Sciences, Kitasato University, ${ }^{a}$ Shirokane, Minato-ku, Tokyo 108, Japan, Hokkaido Institute of Pharmaceutical Sciences, ${ }^{b} 7-1$, Katsuraoka-cho, Otaru-shi, Hokkaido 047-02, Japan, and Department of Chemotherapy, Saitama Cancer Center Research Institute, ${ }^{c}$ Ina, Saitama 362, Japan. Received February 23, 1989

Pyrido[2,3-d]pyrimidines were obtained by treatment of 6-allylaminouracils with $\mathrm{PdCl}_{2}$ at $60^{\circ} \mathrm{C}$, under which conditions the yields of the products were improved to a considerable extent as compared with our previously reported reaction. ${ }^{2)}$ Pyrrolo $[2,3-d]$ pyrimidines were prepared under the above conditions from 6- $(N$-allyl- $N$-methylamino $)$ uracils which were substituted with a methyl group at 6-NH of uracil. In addition, pyrido- and pyrrolo[2,3-d]pyrimidine nucleosides were prepared from 6-(substituted allyl- or $N$-allyl- $N$-methylamino)uridines by adaptation of the above method. That is, the presence or absence of a substituent on the 6-amino group influences the size of ring formed. We proposed plausible pathways to explain why products having different ring sizes were formed.

Keywords ribonucleoside; pyrido[2,3-d]pyrimidine; pyrrolo[2,3-d]pyrimidine; palladium chloride; dehydrocyclization; reaction pathway; Vorbrüggen's ribosylation

Ribonucleosides containing the pyrido[2,3-d]pyrimidine ring system have been synthesized by Broom's ${ }^{3)}$ and Watanabe's) $\mathrm{s}^{4}$ groups. These synthetic compounds $(\mathbf{1}-\mathbf{4})$ can be regarded as analogues of sangivamycin $(5),{ }^{5}$ toyocamycin (6), ${ }^{6)}$ and tubercidin (7), ${ }^{7)}$ which are known to show potent antitumor activity. Our interest in the ring system of these antibiotics prompted us to synthesize pyrido- and pyrrolo[2,3-d]pyrimidines and their nucleosides. Synthesis of these compounds is described herein.

1-Benzyl-6-chlorouracil $(\mathbf{8})^{8)}$ was allowed to react with allylamines or propargylamines to give rise to 6-allylamino1-benzyluracils $(9 \mathbf{9}-\mathbf{d})$ and 1-benzyl-6-propargylaminouracils $(\mathbf{1 1 a}, \mathbf{b})$ in good yields, respectively. The structures were confirmed by spectral (mass spectra (MS) and nuclear magnetic resonance (NMR)) data as well as elemental analysis values.

A stirred mixture of $\mathrm{PdCl}_{2}$ and 6-allylamino-1-benzyluracils $(9 \mathbf{a}-\mathbf{d})$ was heated at $60^{\circ} \mathrm{C}$ in aqueous dioxane to

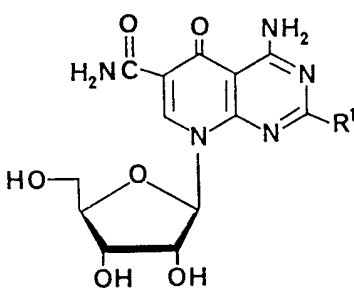

1: $\mathrm{R}^{\mathrm{i}}=\mathrm{H}$

2: $\mathrm{R}^{1}=\mathrm{NH}_{2}$

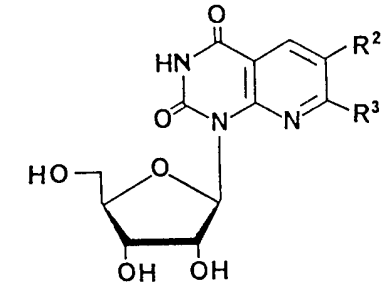

$3: \mathrm{R}^{2}, \mathrm{R}^{3}=\mathrm{H}$

4: $\mathrm{R}^{2}=\mathrm{CONH}_{2}$ $\mathrm{R}^{3}=\mathrm{NH}_{2}$

$$
\text { Fig. toyocamycin } \mathrm{R}^{4}=\mathrm{CN}
$$

give, after standard work-up, 1-benzylpyrido[2,3- $d$ ]pyrimidine-2,4(1H,3H)-diones (10a-d) in fair or good yields $(65 \%, 64 \%, 52 \%$ and $41 \%$, respectively). These data show that yields for the cyclization of $\mathbf{9}$ to $\mathbf{1 0}$ were improved by carrying out the reaction at $60^{\circ} \mathrm{C}$ and using $\mathrm{PdCl}_{2}$ in place of $\mathrm{PdCl}_{2}-\mathrm{CuCl}-\mathrm{O}_{2}$ complex ${ }^{2)}$ which we previously employed.

Compound 11b was hydrogenated with $\mathrm{H}_{2}$ over $5 \%$ $\mathrm{Pd}-\mathrm{BaSO}_{4}$ to afford 12b, and treatment of 8 and $N$ methylallylamine directly gave $\mathbf{1 2 b}$ in good yield. From $\mathbf{1 2 b}$ and $\mathrm{PdCl}_{2}$, pyrrolo[2,3-d]pyrimidine (13b) instead of pyrido[2,3-d]pyrimidine was obtained by cyclization-dehydration under the same conditions as for the formation of 10. The structure assignment rests upon MS, NMR and elemental analysis. In particular, the presence of singlet signals $(\delta, 2.16,3 \mathrm{H}$ and $\delta, 3.48,3 \mathrm{H})$ attributable to $\mathrm{CH}_{3}-\mathrm{C}$ and $\mathrm{CH}_{3}-\mathrm{N}$, respectively, supported the structure assignment.

Ribosylation of 1-benzyl-6-chlorouracil (8) was carried out according to Vorbrüggen's general procedure. ${ }^{9)}$ Thus, $\mathbf{8}$ was heated under reflux with hexamethyldisilazane in acetonitrile. The mixture was allowed to stand at room temperature, then $1-O$-acetyl-2,3,5-tri- $O$-benzoyl- $\beta$-D-ribofuranose and $\mathrm{SnCl}_{4}$ were added to the cooled solution. Work-up afforded 1-benzyl-6-chloro-3-(2',3',5'-tri- $O$-benzoyl- $\beta$-D-ribofuranosyl)uracil (14) in $90 \%$ yield. 1-Benzyl-3$\left(2^{\prime}, 3^{\prime}, 5^{\prime}\right.$-tri- $O$-benzoyl- $\beta$-D-ribofuranosyl)-6-(substituted allylamino)uracils (15a-d) were easily prepared in excellent yield on treatment of $\mathbf{1 4}$ with substituted allylamines.

6-( $N$-Methyl- $N$-propargylamino)-1-benzyl-3-(2', $3^{\prime}, 5^{\prime}$-tri$O$-benzoyl- $\beta$-D-ribofuranosyl)uracil (16), which was obtained by the treatment of $\mathbf{1 4}$ with $N$-methylpropargylamine, was subjected to catalytic hydrogenation over $5 \% \mathrm{Pd}-$ $\mathrm{BaSO}_{4}$ to give 17 in $63 \%$ overall yield.

The allylaminouracil nucleoside derivative (15a) afforded, on treatment with $\mathrm{PdCl}_{2}$ at $60^{\circ} \mathrm{C}, 1$-benzyl-3- $\left(2^{\prime}, 3^{\prime}, 5^{\prime}-\right.$ tri- $O$-benzoyl- $\beta$-D-ribofuranosyl)pyrido[2,3- $d]$ pyrimidine$2,4-(1 H, 3 H)$-dione $(\mathbf{1 8 a})$ in $51 \%$ yield. The structural confirmation rests upon spectral (NMR and MS) as well as elemental analysis. Analogously, 18b, c, d were obtained from $14 \mathbf{b}, \mathbf{c}, \mathbf{d}$ in $61 \%, 39 \%$ and $63 \%$ yields, respectively. 
<smiles></smiles><smiles>[Y]/C(=C\C)C([R])[R]</smiles><smiles>[R]NC(=C)C1CCCCC1C</smiles>

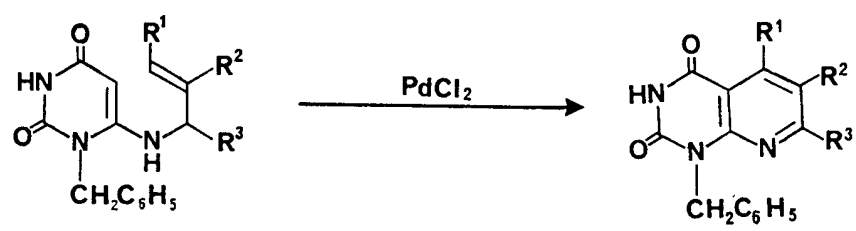

$9 a-d$

$10 \mathrm{a}-\mathrm{d}$

a : $R^{1}, R^{2}, R^{3}=H$

b: $R^{\prime}, R^{2}=H, R^{3}=C_{3}$

c : $R^{1}, R^{3}=H, R^{2}=C_{3}$

d: $\mathrm{R}^{2}, \mathrm{R}^{3}=\mathrm{H}, \mathrm{R}^{1}=\mathrm{CH}_{3}$

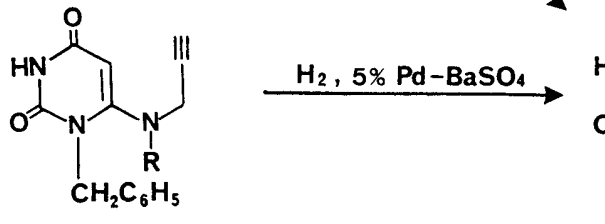<smiles>C=CCN(C)c1cc(=O)[nH]c(=O)n1CCC</smiles>

$12 b$<smiles>CCn1cc(C)c2c(=O)[nH]c(=O)n(CC)c21</smiles>

$13 \mathrm{~b}$

11a: $\mathrm{R}=\mathrm{H}$

11b : $\mathrm{R}=\mathrm{CH}_{3}$

Chart 1

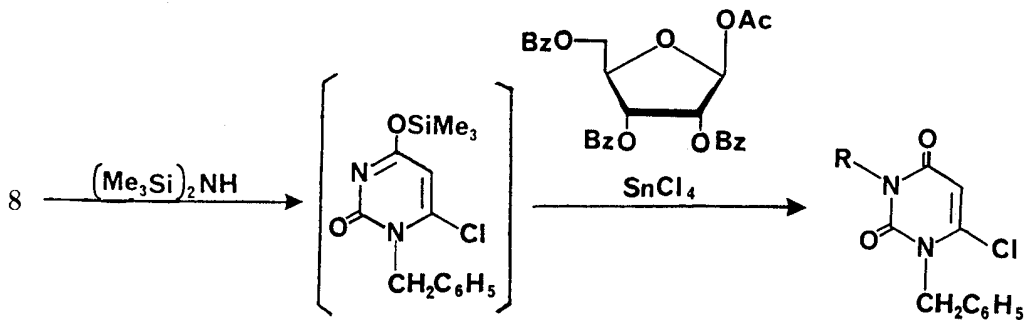

14

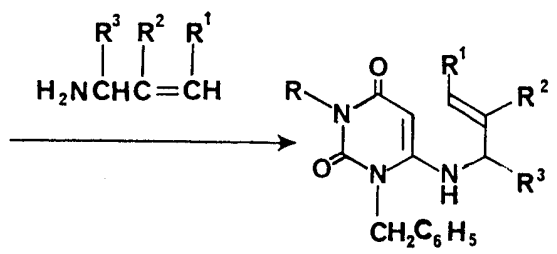

$\mathrm{R}=2^{\prime}, 3^{\prime}, 5^{\prime}$-tri- $O$-benzoyl-

$\beta$ - $D$-ribofuranosyl<smiles>C#CCNC</smiles><smiles>[R]n1c(N(C)CC=C)cc(=O)n(CCCC)c1=O</smiles>

17<smiles>[R]n1c(=O)cc(N(C)CC#C)n(CCCCC)c1=O</smiles>

16

Chart 2

A parallel reaction starting from 17 afforded, after deblocking, 1-benzyl-5,7-dimethyl-3-( $\beta$-D-ribofuranosyl)pyrrolo[2,3- $d$ ]pyrimidine-2,4(1H,3H)-dione (21) instead of the pyrido $[2,3-d]$ pyrimidine derivative.

It is worthy of note that the size of the ring formed by annulation depends on the presence or absence of a substituent on the exo-nitrogen of 6-aminouracils.

We propose that the reaction pathways to pyrido- and pyrrolo[2,3- $d$ ]pyrimidines involve the action of $\mathrm{PdCl}_{2}$ on the allylamino group in the molecule of $6-(N$-substituted allyl- or $N$-allyl- $N$-methylamino)uracils $(\mathbf{9 a}-\mathbf{d}$ and $\mathbf{1 2 b})$ and (15a- d and 17) as follows (Charts 4 and 5).

Regarding the pathway (Chart 4) to pyrrolo[2,3-d]pyrimidines, the $\sigma$-complex, bearing a secondary carbonium ion (d) is produced in preference to the $\sigma$-complex, having a primary carbonium ion (c) in terms of carbonium ion theory, and as a result, pyrrolo[2,3- $d$ ]pyrimidines $(\mathrm{g})$ are obtained by cyclization, $\beta$-elimination and aromatization via intermediates e and $\mathrm{f}$.

On the other hand, regarding the pathway (Chart 5) to 


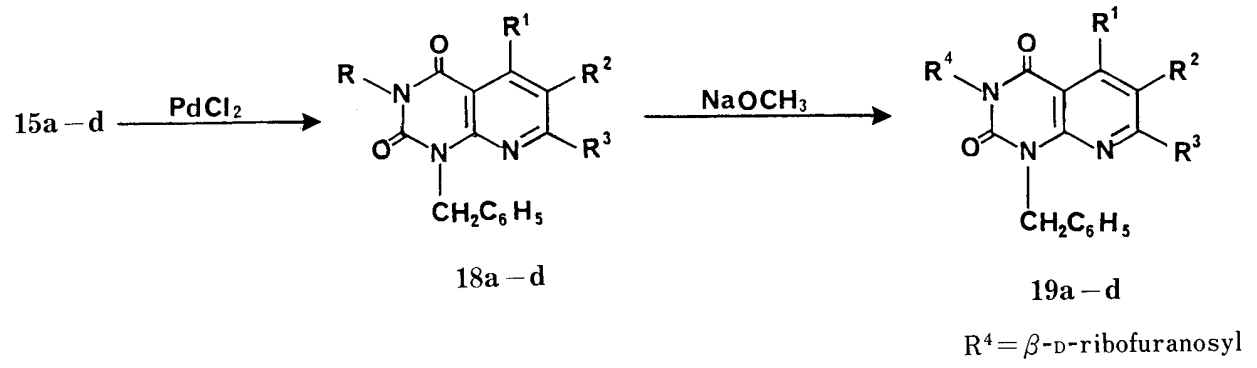

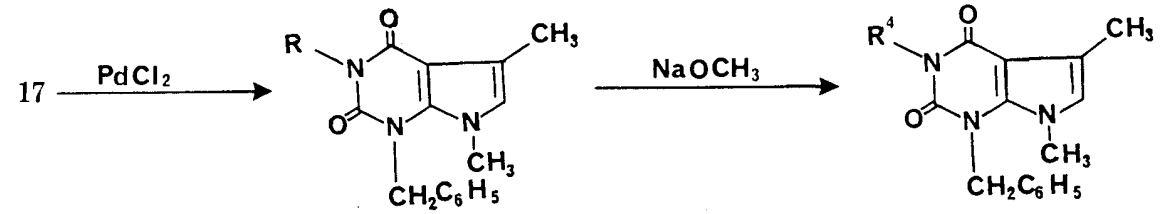

20

21

Chart 3

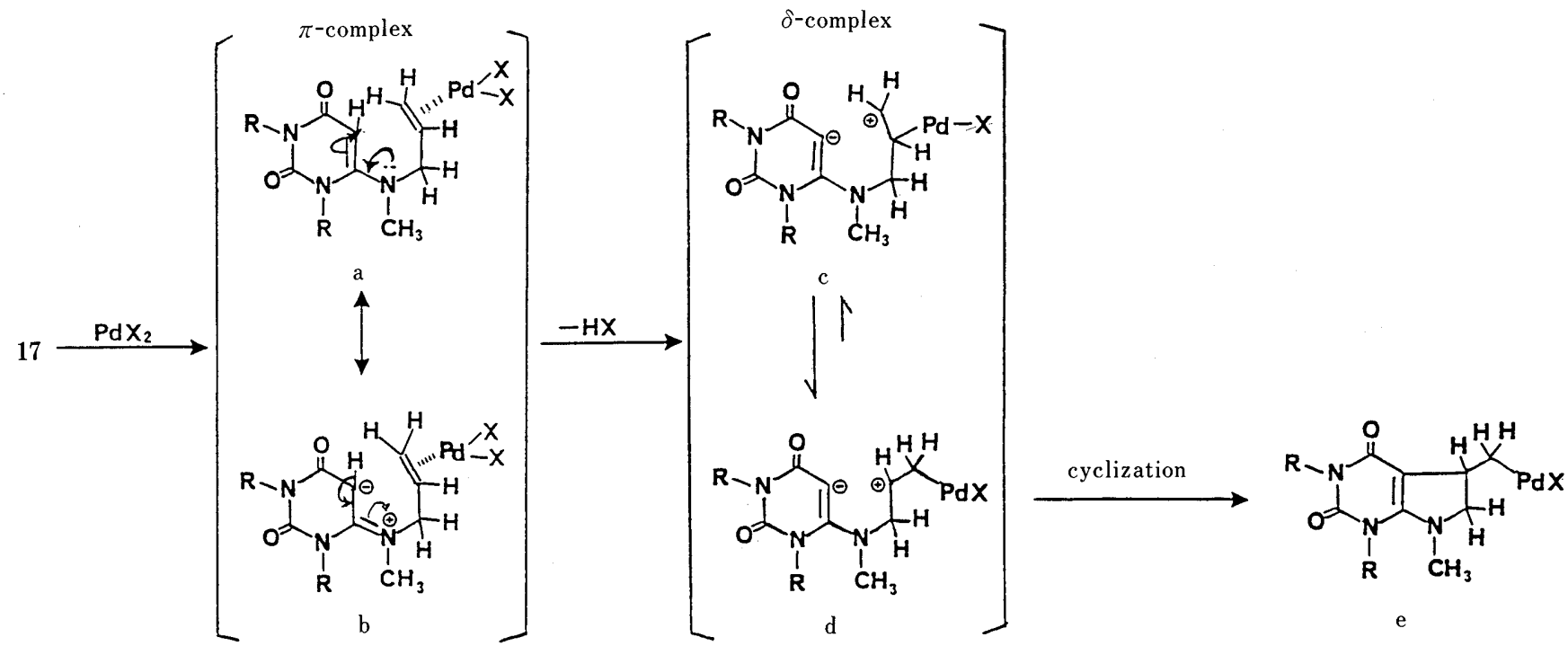<smiles></smiles>

Chart 4. Reaction Pathway to Pyrrolo[2,3- $d$ ]pyrimidine

pyrido[2,3- $d$ ]pyrimidines $(\mathrm{n})$, inspection of the molecular model showed that the anion ( - or $\delta-$ ) on its pyrimidine ring and cation $(+$ or $\delta+)$ of the $\sigma$-complex part in the intermediate (j) can readily combine in preference to combination of the anion $(-$ or $\delta-)$ and cation $(+$ or $\delta+)$ in the intermediate $(\mathrm{k})$ owing to their proximity in $\mathrm{j}$, and the presence of hydrogen on carbon-5 of the pyrimidine ring in the intermediate $(\mathrm{k})$ inhibits combination of the ions.

The pathway from 15 to $\mathrm{n}$ consists of cyclization, $\beta$ elimination and aromatization via intermediates ( 1 and $\mathrm{m})$.
Finally, 1-benzyl-3-( $\beta$-D-ribofuranosyl)pyrido[2,3- $d$ ]pyrimidine-2,4(1H,3H)-diones $(19 \mathrm{a}-\mathrm{d})$ were obtained in excellent yields by treating $18 \mathbf{a}-\mathbf{d}$ with sodium methoxide in $\mathrm{MeOH}$ at $50-60^{\circ} \mathrm{C}$. 1-Benzyl-5,7-dimethyl-3-( $\beta$-D-ribofuranosyl)pyrrolo[2,3- $d$ ]pyrimidine-2,4(1H,3H)-dione (21) was also prepared by hydrolysis of $\mathbf{2 0}$ in a similar manner in $84 \%$ yield. Some of the products, prepared in this study exhibit differentiation-inducing and growth-inhibitory activities toward HL-60 cells. ${ }^{10)}$

The results may be summarized as follows. i) Improve- 


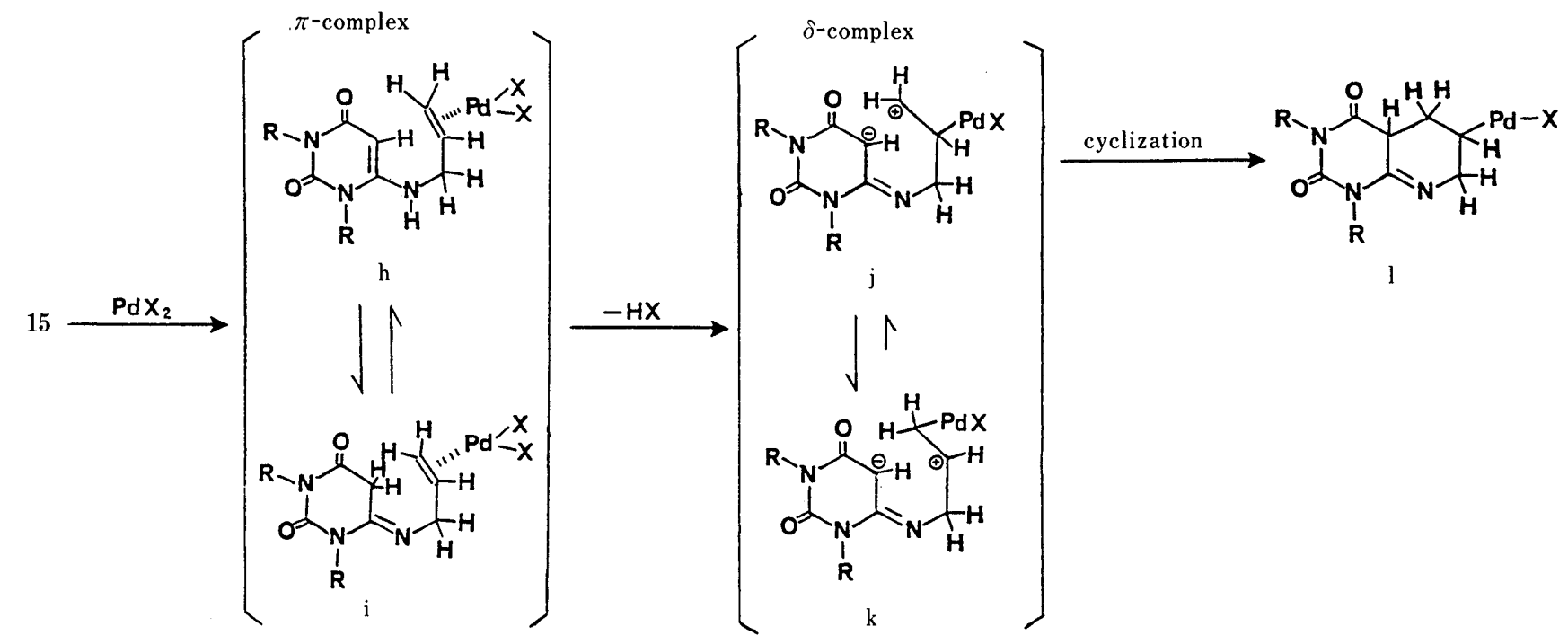

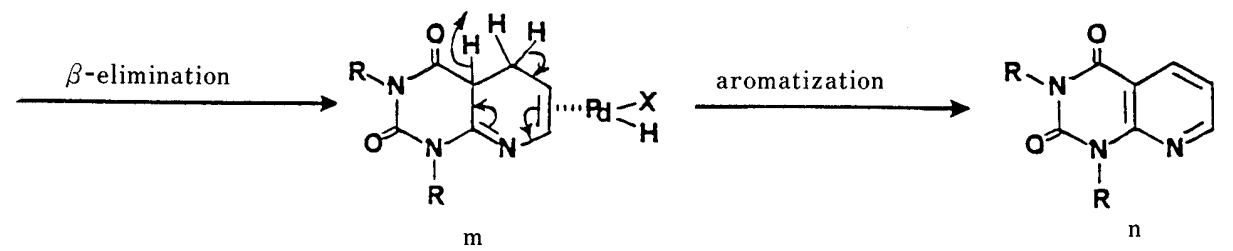

Chart 5. Reaction Pathway to Pyrido[2,3-d]pyrimidine

ment of yields in the syntheses of pyrido[2,3- $d$ ]pyrimidines was achieved. ii) An effective synthetic procedure for pyrrolo[2,3- $d$ ]pyrimidines was developed. iii) Pyrido- and pyrrolo[2,3- $d$ ]pyrimidine nucleosides were prepared by adaptation of the above developed method. iv) Reaction pathways to explain the formation of pyrido- and pyrrolo$[2,3-d]$ pyrimidines are proposed. v) Some of the products showed differentiation-inducing and growth-inhibitory activities toward HL-60 cells. ${ }^{10)}$

\section{Experimental}

General Melting points were determined in a capillary tube and are uncorrected. MS were recorded on a JEOL D-100 instrument. ${ }^{1}$ H-NMR spectra were recorded on a Varian EM-390 NMR spectrometer with $\mathrm{Me}_{4} \mathrm{Si}$ (TMS) as an internal standard in $\mathrm{CDCl}_{3}$ or in dimethyl sulfoxide- $d_{6}$ $\left(\mathrm{DMSO}-d_{6}\right)$. Microanalyses were performed by the staff in the Microanalytical Laboratory of this school.

Column chromatography was performed on Wakogel C-200, and thin layer chromatography (TLC) was performed on Kieselgel $60 \mathrm{GF}_{254}$ (Merck) and spots were detected under ultraviolet (UV) light.

6-Allylamino-1-benzyluracil (9a) A mixture of 1-benzyl-6-chlorouracil (8) $(2.36 \mathrm{~g}, 10 \mathrm{mmol})$ and allylamine $(2.28 \mathrm{~g}, 40 \mathrm{mmol})$ was refluxed for $1.5 \mathrm{~h}$. The reaction mixture was evaporated in vacuo. The residue was dissolved in $\mathrm{CHCl}_{3}$, and this solution was washed with water $(20 \mathrm{ml} \times 2)$, and dried over $\mathrm{Na}_{2} \mathrm{SO}_{4}$. After the solvent was removed, the residue was purified by recrystallization from EtOH to give $2.21 \mathrm{~g}(86 \%)$ of white needles (10a), mp 191-192 ${ }^{\circ} \mathrm{C}$. MS $m / z: 257\left(\mathrm{M}^{+}\right) .{ }^{1} \mathrm{H}-\mathrm{NMR}$ (DMSO- $d_{6}$ ) $\delta: 3.53-3.76\left(2 \mathrm{H}, \mathrm{m},-\mathrm{NHCH}_{2}-\right), 4.43(1 \mathrm{H}, \mathrm{s}, \mathrm{H}-5), 4.90-5.18(2 \mathrm{H}, \mathrm{m}$, $\left.\mathrm{CH}=\mathrm{CH}_{2}\right), 5.10\left(2 \mathrm{H}, \mathrm{s}, \mathrm{C}_{2} \underline{\mathrm{C}}_{6} \mathrm{H}_{5}\right), 5.48-6.00\left(1 \mathrm{H}, \mathrm{m}, \mathrm{CH}=\mathrm{CH}_{2}\right), 6.83$ $\left(1 \mathrm{H}, \mathrm{t},-\mathrm{NHCH}_{2}-, J=6.0 \mathrm{~Hz}\right), 10.45(1 \mathrm{H}, \mathrm{br}, \mathrm{NH}), 7.13-7.41(5 \mathrm{H}, \mathrm{m}$, $\mathrm{CH}_{2} \mathrm{C}_{6} \mathrm{H}_{5}$ ). Anal. Calcd for $\mathrm{C}_{14} \mathrm{H}_{15} \mathrm{~N}_{3} \mathrm{O}_{2}: \mathrm{C}, 65.35 ; \mathrm{H}, 5.88 ; \mathrm{N}, 16.33$. Found: C, 65.30; H, 5.73; N, 16.23.

1-Benzyl-6-( $\alpha$-methylallylamino)uracil (9b) A mixture of $8(2.36 \mathrm{~g}$, $10 \mathrm{mmol})$ and $\alpha$-methylallylamine $(2.84 \mathrm{~g}, 40 \mathrm{mmol})$ was refluxed for $1.5 \mathrm{~h}$. The reaction mixture was worked up in a manner similar to that described above for $9 \mathrm{a}$, giving $9 \mathrm{~b}(1.71 \mathrm{~g}, 63 \%)$ as white prisms, $\mathrm{mp} 233-234^{\circ} \mathrm{C}$. MS $m / z: 271\left(\mathrm{M}^{+}\right) .{ }^{1} \mathrm{H}-\mathrm{NMR}\left(\mathrm{DMSO}-d_{6}\right) \delta: 1.15\left(3 \mathrm{H}, \mathrm{d}, \mathrm{CHCH}_{3}, J=7.0 \mathrm{~Hz}\right)$, $3.87\left(1 \mathrm{H}, \mathrm{q}, \mathrm{NHCHCH}{ }_{3}, J=7.0 \mathrm{~Hz}\right), 4.53(1 \mathrm{H}, \mathrm{s}, \mathrm{H}-5), 4.87-5.13(2 \mathrm{H}, \mathrm{m}$, $\left.\mathrm{CH}=\mathrm{CH}_{2}\right), 5.20\left(2 \mathrm{H}, \mathrm{s}, \mathrm{CH}_{2} \mathrm{C}_{6} \mathrm{H}_{5}\right), 5.50-5.90\left(1 \mathrm{H}, \mathrm{m}, \mathrm{CH}=\mathrm{CH}_{2}\right), 6.26$ $\left(1 \mathrm{H}, \mathrm{d}, \mathrm{NHCHCH}_{3}, J=7.0 \mathrm{~Hz}\right), 7.12-7.43\left(5 \mathrm{H}, \mathrm{m}, \mathrm{CH}_{2} \mathrm{C}_{6} \mathrm{H}_{5}\right), 10.59$ $(1 \mathrm{H}, \mathrm{br}, \mathrm{NH})$. Anal. Calcd for $\mathrm{C}_{15} \mathrm{H}_{17} \mathrm{~N}_{3} \mathrm{O}_{2}: \mathrm{C}, 66.40 ; \mathrm{H}, 6.32 ; \mathrm{N}, 15.49$. Found: C, 66.28; H, 6.24; N, 15.31 .

1-Benzyl-6-( $\beta$-methylallylamino)uracil (9c) A mixture of $8(1.30 \mathrm{~g}$, $5.5 \mathrm{mmol})$ and $\beta$-methylallylamine $(1.42 \mathrm{~g}, 20 \mathrm{mmol})$ was refluxed for $2 \mathrm{~h}$ The reaction mixture was worked up in a manner similar to that described above for $9 \mathrm{a}$, giving $9 \mathrm{c}(1.39 \mathrm{~g}, 93 \%)$ as white needles, $\mathrm{mp} 255-256^{\circ} \mathrm{C}$. MS $m / z: 271\left(\mathrm{M}^{+}\right) .{ }^{1} \mathrm{H}-\mathrm{NMR}$ (DMSO- $\left.d_{6}\right) \delta: 1.52\left(3 \mathrm{H}, \mathrm{s}, \mathrm{CCH}_{3}\right), 3.57(2 \mathrm{H}, \mathrm{d}$, $\left.\mathrm{NHCH}_{2}-, J=5.4 \mathrm{~Hz}\right) .4 .41(1 \mathrm{H}, \mathrm{s}, 5-\mathrm{H}), 4.66,4.77\left(\right.$ each $\left.1 \mathrm{H}, \mathrm{s},-\mathrm{C}=\mathrm{CH}_{2}\right)$, $5.13\left(2 \mathrm{H}, \mathrm{s}, \mathrm{CH}_{2} \mathrm{C}_{6} \mathrm{H}_{5}\right), 6.92\left(1 \mathrm{H}, \mathrm{t}, \mathrm{NHCH}_{2}-J=5.4 \mathrm{~Hz}\right), 7.08-7.51 \cdot(5 \mathrm{H}$, m, $\left.\mathrm{CH}_{2} \mathrm{C}_{6} \underline{\mathrm{H}}_{5}\right), 10.52(1 \mathrm{H}, \mathrm{br}, \mathrm{NH})$. Anal. Calcd for $\mathrm{C}_{15} \mathrm{H}_{17} \mathrm{~N}_{3} \mathrm{O}_{2}$ : C, 66.40; H. 6.32; N, 15.49. Found: C, 66.21; H, 6.34; N, 15.32.

1-Benzyl-6-crotylaminouracil (9d) A mixture of $8(2.36 \mathrm{~g}, 10 \mathrm{mmol})$ and crotylamine $(2.84 \mathrm{~g}, 40 \mathrm{mmol})$ was refluxed for $2 \mathrm{~h}$. The reaction mixture was worked up in a manner similar to that described above for $9 \mathrm{a}$, giving 9d $(2.28 \mathrm{~g}, 84 \%)$ as white needles, mp $234-235^{\circ} \mathrm{C}$. MS $m / z: 271\left(\mathrm{M}^{+}\right) .{ }^{1} \mathrm{H}^{-}$ NMR (DMSO- $\left.d_{6}\right) \delta: 1.61\left(3 \mathrm{H}, \mathrm{d}, \mathrm{CCH}_{3}, J=5.4 \mathrm{~Hz}\right), 3.57(2 \mathrm{H}, \mathrm{br}$, $\left.\mathrm{NHCH}_{2}\right), 4.44(1 \mathrm{H}, \mathrm{s}, 5-\mathrm{H}), 5.02-5.65\left(2 \mathrm{H}, \mathrm{m}, \mathrm{CH}=\mathrm{CHCH}_{3}\right), 6.76(1 \mathrm{H}$, $\left.\mathrm{t}, \mathrm{NHCH}_{2}, J=5.4 \mathrm{~Hz}\right), 7.03-7.49\left(5 \mathrm{H}, \mathrm{m}, \mathrm{CH}_{2} \mathrm{C}_{6} \underline{\mathrm{H}}_{5}\right), 10.46(1 \mathrm{H}, \mathrm{br}, \mathrm{NH})$ Anal. Calcd for $\mathrm{C}_{15} \mathrm{H}_{17} \mathrm{~N}_{3} \mathrm{O}_{2}: \mathrm{C}, 66.40 ; \mathrm{H}, 6.32 ; \mathrm{N}, 15.49$. Found: $\mathrm{C}, 66.30$; $\mathrm{H}, 6.35 ; \mathrm{N}, 15.29$.

1-Benzyl-6-propargylaminouracil (11a) A mixture of $8(2,36 \mathrm{~g}, 10$ $\mathrm{mmol})$ and propargylamine $(2.20 \mathrm{~g}, 40 \mathrm{mmol})$ was refluxed for $1.5 \mathrm{~h}$. The reaction mixture was worked up in a manner similar to that described above for $9 \mathrm{a}$, giving $11 \mathrm{a}(2.04 \mathrm{~g}, 80 \%)$ as white needles, mp $208-209^{\circ} \mathrm{C}$. MS $m / z: 255\left(\mathrm{M}^{+}\right) .{ }^{1} \mathrm{H}-\mathrm{NMR}$ (DMSO- $\left.d_{6}\right) \delta: 3.02(1 \mathrm{H}, \mathrm{t}, \mathrm{C} \equiv \mathrm{CH}, J=$ $2.1 \mathrm{~Hz}), 3.83\left(2 \mathrm{H}, \mathrm{d}, \mathrm{NHCH}_{2}-, J=2.1 \mathrm{~Hz}\right), 4.67(1 \mathrm{H}, \mathrm{s}, \mathrm{H}-5), 5.05(2 \mathrm{H}, \mathrm{s}$, $\left.\mathrm{CH}_{2} \mathrm{C}_{6} \mathrm{H}_{5}\right), 6.70-7.76\left(6 \mathrm{H}, \mathrm{m}, \mathrm{CH}_{2} \mathrm{C}_{6} \mathrm{H}_{5}, \mathrm{NH}\right), 10.65(1 \mathrm{H}, \mathrm{br}, \mathrm{NH})$. Anal. Calcd for $\mathrm{C}_{14} \mathrm{H}_{13} \mathrm{~N}_{3} \mathrm{O}_{2}: \mathrm{C}, 65.87 ; \mathrm{H}, 5.13 ; \mathrm{N}, 16.46$. Found: $\mathrm{C}, 65.65 ; \mathrm{H}$ $5.02 ; \mathrm{N}, 16.28$.

1-Benzyl-6-( $N$-methyl- $N$-propargylamino)uracil (11b) A mixture of 8 $(2.36 \mathrm{~g}, 10 \mathrm{mmol})$ and $N$-methylpropargylamine $(2.76 \mathrm{~g}, 40 \mathrm{mmol})$ was refluxed for $1.5 \mathrm{~h}$. The reaction mixture was worked up in a manner similar to that described above for $9 \mathrm{a}$, giving $11 \mathrm{~b}(1.37 \mathrm{~g}, 51 \%)$ as white needles, mp 132-133 ${ }^{\circ} \mathrm{C}$. MS $m / z: 269\left(\mathrm{M}^{+}\right) .{ }^{1} \mathrm{H}-\mathrm{NMR}$ (DMSO- $\left.d_{6}\right) \delta: 2.65(3 \mathrm{H}, \mathrm{s}$, $\left.\mathrm{NCH}_{3}\right), 3.20(1 \mathrm{H}, \mathrm{t}, \quad \mathrm{C} \equiv \mathrm{CH}, \quad J=2.1 \mathrm{~Hz}), \quad 3.73\left(2 \mathrm{H}, \mathrm{d},-\mathrm{NCH}_{2-}^{-}\right.$, $J=2.1 \mathrm{~Hz}), 4.94\left(2 \mathrm{H}, \mathrm{s}, \mathrm{C}_{2} \mathrm{C}_{6} \mathrm{H}_{5}\right), 5.22(1 \mathrm{H}, \mathrm{s}, \mathrm{H}-5), 7.03-7.44(5 \mathrm{H}, \mathrm{m}$, 
$\left.\mathrm{CH}_{2} \mathrm{C}_{6} \underline{\mathrm{H}}_{5}\right), 11.04(1 \mathrm{H}$, br, $\mathrm{NH})$. Anal. Calcd for $\mathrm{C}_{15} \mathrm{H}_{15} \mathrm{~N}_{3} \mathrm{O}_{2}: \mathrm{C}, 66.90 ; \mathrm{H}$, $5.61 ; \mathrm{N}, 15.61$. Found: $\mathrm{C}, 66.65 ; \mathrm{H}, 5.59 ; \mathrm{N}, 15.48$.

1-Benzyl-6-( $N$-allyl- $N$-methylamino)uracil (12b) i) A mixture of 8 $(2.36 \mathrm{~g}, 10 \mathrm{mmol})$ and $N$-methylallylamine $(2.84 \mathrm{~g}, 40 \mathrm{mmol})$ was refluxed for $2 \mathrm{~h}$. The reaction mixture was worked up in a manner similar to that described above for $9 \mathbf{a}$, giving $\mathbf{1 2 b}(2.12 \mathrm{~g}, 78 \%)$ as white needles, $\mathrm{mp} 153-$ $154^{\circ} \mathrm{C}$. MS $m / z: 271\left(\mathrm{M}^{+}\right) .{ }^{1} \mathrm{H}-\mathrm{NMR}$ (DMSO- $\left.d_{6}\right) \delta: 2.59(3 \mathrm{H}, \mathrm{s}$, $\left.\mathrm{N}\left(\mathrm{CH}_{3}\right) \mathrm{CH}_{2}-\right), 3.46\left(2 \mathrm{H}, \mathrm{d}, \mathrm{N}\left(\mathrm{CH}_{3}\right) \mathrm{Cl}_{2-}, J=6.0 \mathrm{~Hz}\right), 4.96(2 \mathrm{H}, \mathrm{s}$, $\left.\mathrm{CH}_{2} \mathrm{C}_{6} \mathrm{H}_{5}\right), 5.10(1 \mathrm{H}, \mathrm{s}, \mathrm{H}-5), 5.18-5.36\left(2 \mathrm{H}, \mathrm{m}, \mathrm{CH}=\mathrm{CH}_{2}\right), 5.50-5.97$ $\left(1 \mathrm{H}, \mathrm{m}, \mathrm{CH}=\mathrm{CH}_{2}\right), 7.06-7.41\left(5 \mathrm{H}, \mathrm{m}, \mathrm{CH}_{2} \mathrm{C}_{6} \underline{\mathrm{H}}_{5}\right), 10.95(1 \mathrm{H}, \mathrm{br}, \mathrm{NH})$. Anal. Calcd for $\mathrm{C}_{15} \mathrm{H}_{17} \mathrm{~N}_{3} \mathrm{O}_{2}: \mathrm{C}, 66.40 ; \mathrm{H}, 6.32 ; \mathrm{N}, 15.49$. Found: $\mathrm{C}, 66.23$; $\mathrm{H}, 6.58 ; \mathrm{N}, 15.25$

ii) A suspension of $11 \mathrm{~b}(807 \mathrm{mg}, 3 \mathrm{mmol}), 5 \% \mathrm{Pd}^{-\mathrm{BaSO}_{4}}(28 \mathrm{mg})$ and quinoline $(28 \mathrm{mg})$ in $\mathrm{MeOH}(20 \mathrm{ml})$ was bubbled through with hydrogen gas under atmospheric pressure at room temperature for $7 \mathrm{~h}$, then filtered. The solvent was removed from the filtrate in vacuo, and the residue was purified by recrystallization from EtOH to give $12 \mathrm{~b}(716 \mathrm{mg}, 88 \%)$ as white needles, mp 153-154 ${ }^{\circ} \mathrm{C}$. MS $m / z$ : $271\left(\mathrm{M}^{+}\right)$.

1-Benzylpyrido[2,3-d]pyrimidine-2,4(1H,3H)-dione (10a) A mixture of $\mathrm{PdCl}_{2}(177 \mathrm{mg}, 1 \mathrm{mmol})$ and $9 \mathrm{a}(257 \mathrm{mg}, 1 \mathrm{mmol})$ in dioxane $(20 \mathrm{ml})$ and $\mathrm{H}_{2} \mathrm{O}(2 \mathrm{ml})$ was stirred at $60^{\circ} \mathrm{C}$ for $3 \mathrm{~h}$. The reaction mixture was evaporated in vacuo, $\mathrm{CHCl}_{3}(50 \mathrm{ml})$ was added to the crude product and the solution was applied to the top of a funnel $(4 \mathrm{~cm}$ diameter $\times 6)$ containing silica gel which was washed with $\mathrm{CHCl}_{3}-\mathrm{EtOH}(10: 1)$. The $\mathrm{CHCl}_{3}-\mathrm{EtOH}$ eluate was evaporated in vacuo and the residue was recrystallized from $\mathrm{MeOH}$ to give $164 \mathrm{mg}(65 \%)$ of pale yellowish needles (10a), mp 182-183 ${ }^{\circ} \mathrm{C}$. MS $m / z: 253\left(\mathrm{M}^{+}\right) .{ }^{1} \mathrm{H}$-NMR $\left(\mathrm{CDCl}_{3}\right) \delta: 5.50(2 \mathrm{H}$, s, $\left.\mathrm{CH}_{2} \mathrm{C}_{6} \mathrm{H}_{5}\right), 7.23(1 \mathrm{H}, \mathrm{dd}, \mathrm{H}-6, J=7.2,4.5 \mathrm{~Hz}), 7.11-7.61(5 \mathrm{H}, \mathrm{m}$, $\left.\mathrm{CH}_{2} \mathrm{C}_{6} \underline{\mathrm{H}}_{5}\right), 8.46(1 \mathrm{H}, \mathrm{dd}, \mathrm{H}-5, J=7.2,1.8 \mathrm{~Hz}), 8.70(1 \mathrm{H}, \mathrm{dd}, \mathrm{H}-7, J=4.5$, $1.8 \mathrm{~Hz}), 9.38(1 \mathrm{H}, \mathrm{br}, \mathrm{NH})$. Anal. Calcd for $\mathrm{C}_{14} \mathrm{H}_{11} \mathrm{~N}_{3} \mathrm{O}_{2}: \mathrm{C}, 66.39 ; \mathrm{H}, 4.38$; $\mathrm{N}, 16.59$. Found: C, $66.15 ; \mathrm{H}, 4.53 ; \mathrm{N}, 16.36$.

1-Benzyl-7-methylpyrido[2,3-d]pyrimidine-2,4(1 H,3H)-dione (10b) A mixture of $9 \mathbf{b}(542 \mathrm{mg}, 2 \mathrm{mmol})$ and $\mathrm{PdCl}_{2}(354 \mathrm{mg}, 2 \mathrm{mmol})$ in dioxane $(40 \mathrm{ml})$ and $\mathrm{H}_{2} \mathrm{O}(4 \mathrm{ml})$ was stirred at $60^{\circ} \mathrm{C}$ for $14 \mathrm{~h}$. The reaction mixture was worked up in a manner similar to that described above for 10a, giving 10b (340 mg, 64\%) as yellowish crystals, mp 197-198 ${ }^{\circ} \mathrm{C}$. MS m/z: 267 $\left(\mathrm{M}^{+}\right)$. ${ }^{1} \mathrm{H}-\mathrm{NMR}$ (DMSO- $\left.d_{6}\right) \quad \delta: 2.72\left(3 \mathrm{H}, \mathrm{s}, \mathrm{CCH}_{3}\right), 5.31(2 \mathrm{H},-\mathrm{s}$, $\left.\mathrm{CH}_{2} \mathrm{C}_{6} \mathrm{H}_{5}\right), 7.10(1 \mathrm{H}, \mathrm{d}, 6-\mathrm{H}, J=7.8 \mathrm{~Hz}), 7.10-7.40\left(5 \mathrm{H}, \mathrm{m}, \mathrm{CH}_{2} \mathrm{C}_{6} \underline{\mathrm{H}}_{5}\right)$, $8.16(1 \mathrm{H}, \mathrm{d}, 5-\mathrm{H}, J=7.8 \mathrm{~Hz}), 11.70(1 \mathrm{H}, \mathrm{br}, \mathrm{NH})$. Anal. Caled for $\mathrm{C}_{15} \mathrm{H}_{13} \mathrm{~N}_{3} \mathrm{O}_{2}: \mathrm{C}, 67.40 ; \mathrm{H}, 4.90 ; \mathrm{N}, 15.72$. Found: $\mathrm{C}, 67.35 ; \mathrm{H}, 5.13 ; \mathrm{N}$, 15.49 .

1-Benzyl-6-methylpyrido[2,3- $d]$ pyrimidine-2,4(1H,3H)-dione (10c) A mixture of $9 \mathrm{c}(542 \mathrm{mg}, 2 \mathrm{mmol})$ and $\mathrm{PdCl}_{2}(354 \mathrm{mg}, 2 \mathrm{mmol})$ in dioxane $(40 \mathrm{ml})$ and $\mathrm{H}_{2} \mathrm{O}(4 \mathrm{ml})$ was stirred at $60^{\circ} \mathrm{C}$ for $14 \mathrm{~h}$. The reaction mixture was worked up in a manner similar to that described above for 10a, giving $10 \mathrm{c}(280 \mathrm{mg}, 52 \%)$ as pale yellowish needles, $\mathrm{mp} 221-222^{\circ} \mathrm{C}$. MS $\mathrm{m} / z: 267$ $\left(\mathrm{M}^{+}\right) .{ }^{1} \mathrm{H}-\mathrm{NMR}$ (DMSO- $\left.d_{6}\right) \delta: 2.36\left(3 \mathrm{H}, \mathrm{s}, \mathrm{CCH}_{3}\right), 5.37(2 \mathrm{H}, \mathrm{s}$, $\left.\mathrm{CH}_{2} \mathrm{C}_{6} \mathrm{H}_{5}\right), 7.18-7.40\left(5 \mathrm{H}, \mathrm{m}, \mathrm{CH}_{2} \mathrm{C}_{6} \underline{\mathrm{H}}_{5}\right), 8.20(1 \mathrm{H}, \mathrm{d}, \mathrm{H}-5, J=2.4 \mathrm{~Hz})$, $8.52(1 \mathrm{H}, \mathrm{d}, \mathrm{H}-7, J=2.4 \mathrm{~Hz}), 11.75(1 \mathrm{H}, \mathrm{br}, \mathrm{NH})$. Anal. Calcd for $\mathrm{C}_{15} \mathrm{H}_{13} \mathrm{~N}_{3} \mathrm{O}_{2}: \mathrm{C}, 67.40 ; \mathrm{H}, 4.90 ; \mathrm{N}, 15.72$. Found: $\mathrm{C}, 67.26 ; \mathrm{H}, 4.81 ; \mathrm{N}$, 15.55 .

1-Benzyl-5-methylpyrido[2,3- $d]$ pyrimidine-2,4(1H,3H)-dione (10d) A mixture of $9 \mathrm{~d}(271 \mathrm{mg}, 1 \mathrm{mmol})$ and $\mathrm{PdCl}_{2}(177 \mathrm{mg}, 1 \mathrm{mmol})$ in dioxane $(20 \mathrm{ml})$ and $\mathrm{H}_{2} \mathrm{O}(2 \mathrm{ml})$ was stirred at $60^{\circ} \mathrm{C}$ for $14 \mathrm{~h}$. The reaction mixture was worked up in a manner similar to that described above for 10a, giving 10d $(110 \mathrm{mg}, 41 \%)$ as white needles, $\mathrm{mp} 206-207^{\circ} \mathrm{C}$. MS $m / z$ : $267\left(\mathrm{M}^{+}\right)$ ${ }^{1} \mathrm{H}$-NMR (DMSO-d $\left.d_{6}\right) \delta: 2.72\left(3 \mathrm{H}, \mathrm{s}, \mathrm{CCH}_{3}\right), 5.39\left(2 \mathrm{H}, \mathrm{s}, \mathrm{CH}_{2} \mathrm{C}_{6} \mathrm{H}_{5}\right), 7.10$ $(1 \mathrm{H}, \mathrm{d}, \mathrm{H}-6, J=5.1 \mathrm{~Hz}), 7.18-7.40\left(5 \mathrm{H}, \mathrm{m}, \mathrm{CH}_{2} \mathrm{C}_{6} \mathrm{H}_{5}\right), 8.42(1 \mathrm{H}, \mathrm{d}, \mathrm{H}-7$, $J=5.1 \mathrm{~Hz}), 11.60(1 \mathrm{H}, \mathrm{br}, \mathrm{NH})$. Anal. Calcd for $\mathrm{C}_{15} \mathrm{H}_{13} \mathrm{~N}_{3} \mathrm{O}_{2}: \mathrm{C}, 67.40 ; \mathrm{H}$, $4.90 ; \mathrm{N}, 15.72$. Found: $\mathrm{C}, 67.30 ; \mathrm{H}, 5.03 ; \mathrm{N}, 15.54$

1-Benzyl-5,7-dimethylpyrrolo[2,3-d]pyrimidine-2,4(1 H,3H)-dione (13) A mixture of $12 \mathrm{~b}(271 \mathrm{mg}, 1 \mathrm{mmol})$ and $\mathrm{PdCl}_{2}(177 \mathrm{mg}, 1 \mathrm{mmol})$ in dioxane $(20 \mathrm{ml})$ and $\mathrm{H}_{2} \mathrm{O}(2 \mathrm{ml})$ was refluxed for $2 \mathrm{~h}$. The reaction mixture was evaporated in vacuo. The residue was diluted with water and neutralized with saturated $\mathrm{NaHCO}_{3}$ solution. The solution was extracted with AcOEt $(5 \mathrm{ml} \times 3)$, and dried over $\mathrm{MgSO}_{4}$. The AcOEt solution was evaporated in vacuo, and the residue was purified by silica gel column chromatography with $\mathrm{CHCl}_{3}-\mathrm{EtOH}(10: 1)$, and crystallized from $\mathrm{EtOH}$ to give 13 (122 mg, $45 \%$ ) as a white powder, mp $261-262{ }^{\circ} \mathrm{C}$. MS $m / z: 269\left(\mathrm{M}^{+}\right) .{ }^{1} \mathrm{H}-\mathrm{NMR}$ $\left(\right.$ DMSO- $\left.d_{6}\right) \delta: 2.16\left(3 \mathrm{H}, \mathrm{s}, \mathrm{CCH}_{3}\right), 3.48\left(3 \mathrm{H}, \mathrm{s}, \mathrm{NCH}_{3}\right), 5.38(2 \mathrm{H}, \mathrm{s}$, $\left.\mathrm{CH}_{2} \mathrm{C}_{6} \mathrm{H}_{5}\right), 6.27(1 \mathrm{H}, \mathrm{s}, \mathrm{H}-6), 7.06-7.42\left(5 \mathrm{H}, \mathrm{m}, \mathrm{CH}_{2} \mathrm{C}_{6} \mathrm{H}_{5}\right), 10.75(1 \mathrm{H}$, br, NH). Anal. Calcd for $\mathrm{C}_{15} \mathrm{H}_{15} \mathrm{~N}_{3} \mathrm{O}_{2}: \mathrm{C}, 66.90 ; \mathrm{H}, 5.61 ; \mathrm{N}, 15.61$. Found: C, 66.66; H, 5.48; N, 15.36 .

1-Benzyl-6-chloro-3-(2', $3^{\prime}, 5^{\prime}$-tri- $O$-benzoyl- $\beta$-D-ribofuranosyl)uracil (14) Well-ground $8(2.36 \mathrm{~g}, 10 \mathrm{mmol})$ was suspended in hexamethyl- disilazane $(10 \mathrm{ml})$ and $\mathrm{CH}_{3} \mathrm{CN}(10 \mathrm{ml})$. The suspension was heated under reflux for 20 min until a clear solution resulted. The excess hexamethyldisilazane and $\mathrm{CH}_{3} \mathrm{CN}$ were removed under reduced pressure and the residue was redissolved in anhydrous $\mathrm{CH}_{3} \mathrm{CN}(20 \mathrm{ml})$. This solution was mixed with 1- $O$-acetyl-2,3,5-tri- $O$-benzoyl- $\beta$-D-ribofuranose $(5.04 \mathrm{~g}$, $10 \mathrm{mmol})$. To the cooled solution, $\mathrm{SnCl}_{4}(2.10 \mathrm{~g}, 8 \mathrm{mmol})$ in anhydrous $\mathrm{CH}_{3} \mathrm{CN}(10 \mathrm{ml})$ was added dropwise with stirring, under cooling in an ice bath (the temperature of the reaction mixture should be kept below $\left.10^{\circ} \mathrm{C}\right)$. The resulting clear solution was stirred for another hour, and then the ice bath was removed and the reaction mixture was stirred for an additional $40 \mathrm{~h}$ at room temperature.

The reaction mixture was evaporated in vacuo. The residue was dissolved in anhydrous benzene $(30-40 \mathrm{ml})$, and the solution was applied to the top of a funnel $(4 \mathrm{~cm}$ diameter $\times 6)$ containing silica gel, which was washed with benzene. The benzene eluate was evaporated in vacuo, and the residue was recrystallized from hexane to give $6.12 \mathrm{~g}(90 \%)$ of colorless needles (14), mp $79-80^{\circ} \mathrm{C}$. MS $m / z: 680\left(\mathrm{M}^{+}\right) .{ }^{1} \mathrm{H}-\mathrm{NMR}\left(\mathrm{CDCl}_{3}\right) \delta$ : $4.56-4.90\left(3 \mathrm{H}, \mathrm{m}, \mathrm{H}-4^{\prime}, \mathrm{H}-5^{\prime}\right), 5.12\left(2 \mathrm{H}, \mathrm{s}, \mathrm{CH}_{2} \mathrm{C}_{6} \mathrm{H}_{5}\right), 5.83(1 \mathrm{H}, \mathrm{s}, \mathrm{H}-5)$, $6.18-6.37\left(2 \mathrm{H}, \mathrm{m}, \mathrm{H}-2^{\prime}, \mathrm{H}-3^{\prime}\right), 6.70\left(1 \mathrm{H}, \mathrm{s}, \mathrm{H}^{-1} \mathbf{1}^{\prime}\right), 7.10-7.60,7.80-8.20$ $\left(20 \mathrm{H}, \mathrm{m}, \mathrm{C}_{6} \mathrm{H}_{5} \times 4\right)$. Anal. Calcd for $\mathrm{C}_{37} \mathrm{H}_{29} \mathrm{ClN}_{2} \mathrm{O}_{9}: \mathrm{C}, 65.24 ; \mathrm{H}, 4.29$; $\mathrm{N}, 4.11 ; \mathrm{Cl}, 5.20$. Found $\mathrm{C}, 65.53 ; \mathrm{H}, 4.51 ; \mathrm{N}, 3.99 ; \mathrm{Cl}, 4.98$.

General Procedure for the Syntheses of 1-Benzyl-3- $\left(2^{\prime}, 3^{\prime}, 5^{\prime}\right.$-tri- $O$-benzoyl- $\beta$-D-ribofuranosyl)-6-(substituted allyl- or propargylamino)uracils (15a-d and 16) A gently stirred solution of $14(13.60 \mathrm{~g}, 20 \mathrm{mmol})$ and a substituted allylamine or propargylamine $(0.2 \mathrm{~mol})$ was refluxed for $1.5 \mathrm{~h}$. The reaction mixture was concentrated in vacuo, then the residue was dissolved in anhydrous benzene $(30 \mathrm{ml})$ and the solution was applied to the top of a funnel $(4 \mathrm{~cm}$ diameter $\times 6)$ containing silica gel, which was washed with benzene. After removal of the solvent from the eluate, the residue was purified by crystallization from an appropriate solvent.

6-Allylamino-1-benzyl-3-( $2^{\prime}, 3^{\prime}, 5^{\prime}$-tri- $O$-benzoyl- $\beta$-D-ribofuranosyl)uracil (15a) According to the general procedure, the crude product was obtained from $14(13.60 \mathrm{~g}, 20 \mathrm{mmol})$ and allylamine $(11.16 \mathrm{~g}, 0.2 \mathrm{~mol})$, and recrystallized from $\mathrm{MeOH}-\mathrm{H}_{2} \mathrm{O}(5: 1)$ to give $13.32 \mathrm{~g}(95 \%)$ of colorless prisms $(15 a), \mathrm{mp} 90-92{ }^{\circ} \mathrm{C}$. MS $\mathrm{m} / z: 701\left(\mathrm{M}^{+}\right) .{ }^{1} \mathrm{H}-\mathrm{NMR}\left(\mathrm{CDCl}_{3}\right) \delta$ : $3.45-3.67\left(2 \mathrm{H}, \mathrm{m}, \mathrm{NHCH}_{2}-\right), 4.43-5.12\left(5 \mathrm{H}, \mathrm{m}, \mathrm{CH}=\mathrm{C}_{2}, \mathrm{H}_{2}-4^{\prime}, \mathrm{H}-5^{\prime}\right)$, $4,80(1 \mathrm{H}, \mathrm{s}, \mathrm{H}-5), 5.15\left(2 \mathrm{H}, \mathrm{s}, \mathrm{CH}_{2} \mathrm{C}_{6} \mathrm{H}_{5}\right), 5.40-5.98\left(2 \mathrm{H}, \mathrm{m}, \mathrm{CH}=\mathrm{CH}_{2}\right.$, $\mathrm{NH}), 6.18-6.31\left(2 \mathrm{H}, \mathrm{m}, \mathrm{H}-2^{\prime}, \mathrm{H}-3^{\prime}\right), 6.76\left(1 \mathrm{H}, \mathrm{s}, \mathrm{H}-1^{\prime}\right), 7.10-7.65$, $7.67-8.20\left(20 \mathrm{H}, \mathrm{m}, \mathrm{C}_{6} \mathrm{H}_{5} \times 4\right)$. Anal. Calcd for $\mathrm{C}_{40} \mathrm{H}_{35} \mathrm{~N}_{3} \mathrm{O}_{9}: \mathrm{C}, 68.46 ; \mathrm{H}$, $5.03 ; \mathrm{N}, 5.99$. Found: $\mathrm{C}, 68.31 ; \mathrm{H}, 5.12 ; \mathrm{N}, 5.77$

1-Benzyl-6-( $\alpha$-methylallylamino)-3-( $2^{\prime}, 3^{\prime}, 5^{\prime}$-tri- $O$-benzoyl- $\beta$-D-ribofuranosyl)uracil (15b) According to the general procedure, the crude product was obtained from $14(13.60 \mathrm{~g}, 20 \mathrm{mmol})$ and $\alpha$-methylallylamine $(14.20 \mathrm{~g}, 0.2 \mathrm{~mol})$, and recrystallized from $\mathrm{MeOH}-\mathrm{H}_{2} \mathrm{O}(5: 1)$ to give $11.87 \mathrm{~g}(83 \%)$ of white needles $(\mathbf{1 5 b}), \mathrm{mp} 82-83^{\circ} \mathrm{C}$. MS $m / z: 715\left(\mathrm{M}^{+}\right)$. ${ }^{1} \mathrm{H}-\mathrm{NMR}\left(\mathrm{CDCl}_{3}\right) \delta: 1.10\left(3 \mathrm{H}, \mathrm{d}, \mathrm{CHCH}_{3}, J=6.0 \mathrm{~Hz}\right), 4.26(1 \mathrm{H}, \mathrm{q}$, $\left.\mathrm{NHCHCH}_{3}, J=6.0 \mathrm{~Hz}\right), 4.56-4.78\left(3 \mathrm{H}, \mathrm{m}, \mathrm{H}-4^{\prime}, \mathrm{H}-5^{\prime}\right), 4.82(1 \mathrm{H}, \mathrm{s}, \mathrm{H}-5)$, $4.97-5.26\left(2 \mathrm{H}, \mathrm{m}, \mathrm{CH}=\mathrm{CH}_{2}\right), 5.18\left(2 \mathrm{H}, \mathrm{s}, \mathrm{CH}_{2} \mathrm{C}_{6} \mathrm{H}_{5}\right), 5.33-5.80(2 \mathrm{H}, \mathrm{m}$, $\left.\mathrm{C} \underline{\mathrm{H}}=\mathrm{CH}_{2}, \mathrm{NH}\right), 6.14-6.36\left(2 \mathrm{H}, \mathrm{m}, \mathrm{H}-2^{\prime}, \mathrm{H}-3^{\prime}\right), 6.80\left(1 \mathrm{H}, \mathrm{s}, \mathrm{H}-1^{\prime}\right)$, 7.17-7.56, 7.87-8.16 $\left(20 \mathrm{H}, \mathrm{m}, \mathrm{C}_{6} \mathrm{H}_{5} \times 4\right)$. Anal. Calcd for $\mathrm{C}_{41} \mathrm{H}_{37} \mathrm{~N}_{3} \mathrm{O}_{9}$ : C, $68.80 ; \mathrm{H}, 5.21 ; \mathrm{N}, 5.87$. Found: C, 68.84; H, 5.18; N, 5.57.

1-Benzyl-6- $(\beta$-methylallylamino $)-3-\left(2^{\prime}, 3^{\prime}, 5^{\prime}\right.$-tri- $O$-benzoyl- $\beta$-D-ribofuranosyl)uracil $(15 \mathrm{c})$ According to the general procedure, the crude product was obtained from $14(13.60 \mathrm{~g}, 20 \mathrm{mmol})$ and $\beta$-methylallylamine $(14.20 \mathrm{~g}, 0.2 \mathrm{~mol})$, and recrystallized from $\mathrm{MeOH}-\mathrm{H}_{2} \mathrm{O}(5: 1)$ to give $13.16 \mathrm{~g}(92 \%)$ of pale yellowish needles $(\mathbf{1 5 c}), \mathrm{mp} 96-97^{\circ} \mathrm{C}$. MS $m / z: 715$ $\left(\mathrm{M}^{+}\right) .{ }^{1} \mathrm{H}-\mathrm{NMR}\left(\mathrm{CDCl}_{3}\right) \delta: 1.51\left(3 \mathrm{H}, \mathrm{s}, \mathrm{CCH}_{3}\right), 3.40-3.52(2 \mathrm{H}, \mathrm{m}$, $\left.\mathrm{NHCH}_{2}-\right), 4.40-4.85\left(5 \mathrm{H}, \mathrm{m},-\mathrm{C}=\mathrm{CH}_{2}, \mathrm{H}-4^{\prime}, \mathrm{H}-5^{\prime}\right), 4.77(1 \mathrm{H}, \mathrm{s}, \mathrm{H}=5)$, $5.18\left(3 \mathrm{H}, \mathrm{br}, \mathrm{C}_{2} \mathrm{C}_{6} \mathrm{H}_{5}, \mathrm{NH}\right), 6.20-6.33\left(2 \mathrm{H}, \mathrm{m}, \mathrm{H}-2^{\prime}, \mathrm{H}-3^{\prime}\right), 6.78(1 \mathrm{H}, \mathrm{s}$, $\left.\mathrm{H}-1^{\prime}\right), 7.17-7.57,7.81-8.20\left(20 \mathrm{H}, \mathrm{m}, \mathrm{C}_{6} \mathrm{H}_{5} \times 4\right)$. Anal. Calcd for $\mathrm{C}_{41} \mathrm{H}_{37} \mathrm{~N}_{3} \mathrm{O}_{9}: \mathrm{C}, 68.80 ; \mathrm{H}, 5.21 ; \mathrm{N}, 5.87$. Found: $\mathrm{C}, 68.79 ; \mathrm{H}, 5.33 ; \mathrm{N}, 5.81$.

1-Benzyl-6-crotylamino-3-(2', $3^{\prime}, 5^{\prime}$-tri- $O$-benzoyl- $\beta$-D-ribofuranosyl)uracil (15d) According to the general procedure, the crude product was obtained from $14(13.60 \mathrm{~g}, 20 \mathrm{mmol})$ and crotylamine $(14.20 \mathrm{~g}, 0.2 \mathrm{~mol})$, and recrystallized from $\mathrm{MeOH}-\mathrm{H}_{2} \mathrm{O}(5: 1)$ to give $10.30 \mathrm{~g}(72 \%)$ of slightly yellowish prisms (15d), mp 68-70 ${ }^{\circ} \mathrm{C}$. MS $m / z$ : $715\left(\mathrm{M}^{+}\right) .{ }^{1} \mathrm{H}-\mathrm{NMR}$ $\left(\mathrm{CDCl}_{3}\right) \delta: 1.58\left(3 \mathrm{H}, \mathrm{d}, \mathrm{CCH}_{3}, J=4.8 \mathrm{~Hz}\right), 3.32-3.61\left(2 \mathrm{H}, \mathrm{m}, \mathrm{NHCH}_{2}-\right)$, $3.98(1 \mathrm{H}, \mathrm{br}, \mathrm{NH}), 4.47-4.83\left(3 \mathrm{H}, \mathrm{m}, \mathrm{H}-4^{\prime}, \mathrm{H}-5^{\prime}\right), 4.72(1 \mathrm{H}, \mathrm{s}, \mathrm{H}-5), 5.12$ $\left(2 \mathrm{H}, \mathrm{s}, \mathrm{CH}_{2} \mathrm{C}_{6} \mathrm{H}_{5}\right), 5.17-5.68\left(2 \mathrm{H}, \mathrm{m}, \mathrm{CH}=\mathrm{CHCH}_{3}\right), 6.17-6.36(2 \mathrm{H}$, $\left.\mathrm{m}, \mathrm{H}-2^{\prime}, \mathrm{H}-3^{\prime}\right), 6.74\left(1 \mathrm{H}, \mathrm{s}, \mathrm{H}-1^{\prime}\right), 7.10-7.62,7.67-8.20(20 \mathrm{H}, \mathrm{m}$, $\left.\mathrm{C}_{6} \mathrm{H}_{5} \times 4\right)$. Anal. Caled for $\mathrm{C}_{41} \mathrm{H}_{37} \mathrm{~N}_{3} \mathrm{O}_{9}: \mathrm{C}, 68.80 ; \mathrm{H}, 5.21 ; \mathrm{N}, 5.87$. Found: C, 68.87; H, 5.35; N, 6.01.

1-Benzyl-6-( $N$-methyl- $N$-propargylamino)-3-(2', $3^{\prime}, 5^{\prime}$-tri- $O$-benzoyl- $\beta$-Dribofuranosyl)uracil (16) According to the general procedure, the crude product was obtained from $14(13.60 \mathrm{~g}, 20 \mathrm{mmol})$ and $N$-methyl- 
propargylamine $(13.8 \mathrm{~g}, 0.2 \mathrm{~mol})$, and recrystallized from $\mathrm{MeOH}-\mathrm{H}_{2} \mathrm{O}$ (5:1) to give $10.70 \mathrm{~g}(75 \%)$ of white needles. $\mathrm{mp} 79-80^{\circ} \mathrm{C} \mathrm{(16).} \mathrm{MS} \mathrm{m} / \mathrm{z}$ : $713\left(\mathrm{M}^{+}\right) .{ }^{1} \mathrm{H}-\mathrm{NMR}\left(\mathrm{CDCl}_{3}\right) \delta: 2.35(1 \mathrm{H}, \mathrm{t}, \mathrm{C} \equiv \mathrm{CH}, J=2.4 \mathrm{~Hz}), 2.70$ $\left(3 \mathrm{H}, \mathrm{s}, \mathrm{NCH}_{3}\right), 3.58\left(2 \mathrm{H}, \mathrm{d},-\mathrm{NCH}_{2}-, J=2.4 \mathrm{~Hz}\right), 4.51-4.82\left(3 \mathrm{H}, \mathrm{m}, \mathrm{H}-4^{\prime}\right.$ $\left.\mathrm{H}-5^{\prime}\right), 5.07\left(2 \mathrm{H}, \mathrm{s}, \mathrm{CH}_{2} \mathrm{C}_{6} \mathrm{H}_{5}\right), 5.44(1 \mathrm{H}, \mathrm{s}, \mathrm{H}-5), 6.13-6.26\left(2 \mathrm{H}, \mathrm{m}, \mathrm{H}-2^{\prime}\right.$, $\left.\mathrm{H}-3^{\prime}\right), 6.70\left(1 \mathrm{H}, \mathrm{s}, \mathrm{H}-1^{\prime}\right), 7.16-7.62,7.84-8.20\left(20 \mathrm{H}, \mathrm{m}, \mathrm{C}_{6} \mathrm{H}_{5} \times 4\right)$. Anal. Calcd for $\mathrm{C}_{41} \mathrm{H}_{35} \mathrm{~N}_{3} \mathrm{O}_{9}: \mathrm{C}, 68.99 ; \mathrm{H}, 4.94 ; \mathrm{N}, 5.88$. Found: $\mathrm{C}, 68.77 ; \mathrm{H}$ $4.90 ; \mathrm{N}, 5.65$.

6-( $N$-Allyl- $N$-methylamino)-1-benzyl-3-( $2^{\prime}, 3^{\prime}, 5^{\prime}$-tri- $O$-benzoyl- $\beta$-D-ribofuranosyl)uracil (17) A suspension of $16(3.71 \mathrm{~g}, 5.2 \mathrm{mmol}), 5 \% \mathrm{Pd}$ $\mathrm{BaSO}_{4}(49 \mathrm{mg})$ and quinoline $(49 \mathrm{mg})$ in benzene $(25 \mathrm{ml})$ and EtOH $(25 \mathrm{ml})$ was bubbled through with hydogen gas under atmospheric pressure at room temperature for $24 \mathrm{~h}$. The reaction mixture was evaporated in vacuo. The residue was dissolved in anhydrous benzene $(50 \mathrm{ml})$ and the solution was applied to the top of a funnel $(4 \mathrm{~cm}$ diameter $\times 6)$ containing silica gel, which was washed with benzene. After removal of the solvent from the eluate, the residue was purified by crystallization from $\mathrm{MeOH}-\mathrm{H}_{2} \mathrm{O}(5: 1)$ to give $3.16 \mathrm{~g}\left(85^{\circ}\right)$ of white needles (17), $\mathrm{mp} 62-63^{\circ} \mathrm{C}$. MS $m / z: 715$ $\left(\mathrm{M}^{+}\right) .{ }^{1} \mathrm{H}-\mathrm{NMR}\left(\mathrm{CDCl}_{3}\right) \delta: 2.46\left(3 \mathrm{H}, \mathrm{s}, \mathrm{NCH}_{3}\right), 3.36-3.51(2 \mathrm{H}, \mathrm{m}$, $\left.\mathrm{NCH}_{2}-\right), 4.53-4.76\left(3 \mathrm{H}, \mathrm{m}, \mathrm{H}-4^{\prime}, \mathrm{H}-5^{\prime}\right), 5.05\left(3 \mathrm{H}, \mathrm{s}, \mathrm{CH}_{2} \mathrm{C}_{6} \mathrm{H}_{5}, \mathrm{H}-5\right)$, 5.23-5.34 $\left(2 \mathrm{H}, \mathrm{m}, \mathrm{CH}=\mathrm{CH}_{2}\right), 5.41-5.98\left(1 \mathrm{H}, \mathrm{m}, \mathrm{C} \underline{\mathrm{H}}=\mathrm{CH}_{2}\right), 6.14-$ $6.29\left(2 \mathrm{H}, \mathrm{m}, \mathrm{H}-2^{\prime}, \mathrm{H}-3^{\prime}\right), 6.68\left(1 \mathrm{H}, \mathrm{s}, \mathrm{H}-1^{\prime}\right), 7.10-7.61,7.83-8.18(20 \mathrm{H}$, m, $\left.\mathrm{C}_{6} \mathrm{H}_{5} \times 4\right)$. Anal. Calcd for $\mathrm{C}_{41} \mathrm{H}_{37} \mathrm{~N}_{3} \mathrm{O}_{9}: \mathrm{C}, 68.80 ; \mathrm{H}, 5.21 ; \mathrm{N}, 5.87$. Found C, 68.58; H, 5.30; N, 5.86.

General Procedure for the Dehydrocyclization of 1-Benzyl-6-(substituted allylamino)-3-(2, $3^{\prime}, 5^{\prime}$-tri- $O$-benzoyl- $\beta$-D-ribofuranosyl)uracils $(15 \mathrm{a}-$ d) A mixture of $\mathrm{PdCl}_{2}(177 \mathrm{mg}, 1 \mathrm{mmol})$ in dioxane $(20 \mathrm{ml})$ and $\mathrm{H}_{2} \mathrm{O}$ $(2 \mathrm{ml})$ and the corresponding $15 \mathrm{a}-\mathrm{d}(1 \mathrm{mmol})$ was stirred at $60^{\circ} \mathrm{C}$ for $3 \mathrm{~h}$. The reaction mixture was evaporated in vacuo and the residue was dissolved in benzene $(50 \mathrm{ml})$. The solution was applied to the top of a funnel $(4 \mathrm{~cm}$ diameter $\times 6)$ containing silica gel, which was washed with benzene. After removal of the solvent from the eluate, the residue was purified by crystallization from an appropriate solvent.

1-Benzyl-3- $\left(2^{\prime}, 3^{\prime}, 5^{\prime}\right.$-tri- $O$-benzoyl- $\beta$-D-ribofuranosyl)pyrido[2,3-d]pyrimidine-2,4(1H,3H)-dione (18a) According to the general procedure, the crude product was obtained from $15 \mathrm{a}(701 \mathrm{mg}, 1 \mathrm{mmol})$, and recrystallized from $\mathrm{MeOH}-\mathrm{H}_{2} \mathrm{O}(5: 1)$ to give $355 \mathrm{mg}(51 \%)$ of slightly yellowish crystals (18a), mp $78-80^{\circ} \mathrm{C}$. MS $\mathrm{m} / \mathrm{z}: 697\left(\mathrm{M}^{+}\right) .{ }^{1} \mathrm{H}-\mathrm{NMR}$ $\left(\mathrm{CDCl}_{3}\right) \delta: 4.54-4.83\left(3 \mathrm{H}, \mathrm{m}, \mathrm{H}-4^{\prime}, \mathrm{H}-5^{\prime}\right), 5.52\left(2 \mathrm{H}, \mathrm{s}, \mathrm{CH}_{2} \mathrm{C}_{6} \mathrm{H}_{5}\right), 6.14-$ $6.43\left(2 \mathrm{H}, \mathrm{m}, \mathrm{H}-2^{\prime}, \mathrm{H}-3^{\prime}\right), 6.78\left(1 \mathrm{H}, \mathrm{s}, \mathrm{H}-1^{\prime}\right), 7.18(1 \mathrm{H}, \mathrm{dd}, \mathrm{H}-6, J=7.8$, $4.8 \mathrm{~Hz}), 7.10-7.65,7.80-8.20\left(20 \mathrm{H}, \mathrm{m}, \mathrm{C}_{6} \mathrm{H}_{5} \times 4\right), 8.45(1 \mathrm{H}, \mathrm{dd}, \mathrm{H}-5, J=$ $7.8,1.8 \mathrm{~Hz}), 8.65(1 \mathrm{H}, \mathrm{dd}, \mathrm{H}-7, J=4.8,1.8 \mathrm{~Hz})$. Anal. Calcd for $\mathrm{C}_{40} \mathrm{H}_{31} \mathrm{~N}_{3} \mathrm{O}_{9}$ : C, 68.86; H, 4.47; N, 6.02. Found: $\mathrm{C}, 69.13 ; \mathrm{H}, 4.63 ; \mathrm{N}, 5.79$.

1-Benzyl-7-methyl-3- $\left(2^{\prime}, 3^{\prime}, 5^{\prime}\right.$-tri-O-benzoyl- $\beta$-D-ribofuranosyl)pyrido[2,3- $d$ ]pyrimidine-2,4(1H,3H)-dione (18b) According to the general procedure, the crude product was obtained from $15 \mathrm{~b}(715 \mathrm{mg}, 1 \mathrm{mmol})$, and recrystallized from $\mathrm{MeOH}-\mathrm{H}_{2} \mathrm{O}(5: 1)$ to give $434 \mathrm{mg}(61 \%)$ of white crystals $(\mathbf{1 8 b}), \mathrm{mp} 83-85^{\circ} \mathrm{C}$. MS $m / z: 711\left(\mathrm{M}^{+}\right) .{ }^{1} \mathrm{H}-\mathrm{NMR}\left(\mathrm{CDCl}_{3}\right) \delta$ : $2.60\left(3 \mathrm{H}, \mathrm{s}, \mathrm{CCH}_{3}\right), 4.54-4.81\left(3 \mathrm{H}, \mathrm{m}, \mathrm{H}-4^{\prime}, \mathrm{H}-5^{\prime}\right), 5.52(2 \mathrm{H}, \mathrm{s}$, $\left.\mathrm{CH}_{2} \mathrm{C}_{6} \mathrm{H}_{5}\right), 6.13-6.39\left(2 \mathrm{H}, \mathrm{m}, \mathrm{H}-2^{\prime}, \mathrm{H}-3^{\prime}\right), 6.79\left(1 \mathrm{H}, \mathrm{s}, \mathrm{H}-1^{\prime}\right), 7.03(1 \mathrm{H}, \mathrm{d}$, $\mathrm{H}-6, J=7.8 \mathrm{~Hz}), 7.15-7.66,7.80-8.20\left(20 \mathrm{H}, \mathrm{m}, \mathrm{C}_{6} \mathrm{H}_{5} \times 4\right), 8.31(1 \mathrm{H}, \mathrm{d}$, $\mathrm{H}-5, J=7.8 \mathrm{~Hz}$ ): Anal. Calcd for $\mathrm{C}_{41} \mathrm{H}_{33} \mathrm{~N}_{3} \mathrm{O}_{9}: \mathrm{C}, 69.19 ; \mathrm{H}, 4.67 ; \mathrm{N}, 5.90$. Found: C, 69.43; H, 4.91; N, 5.67.

1-Benzyl-6-methyl-3-( $2^{\prime}, 3^{\prime}, 5^{\prime}$-tri- $O$-benzoyl- $\beta$-D-ribofuranosyl)pyrido$[2,3-d]$ pyrimidine-2,4(1H,3H)-dione (18c) According to the general procedure, the crude product was obtained from $15 \mathrm{c}(715 \mathrm{mg}, 1 \mathrm{mmol})$, and recrystallized from $\mathrm{MeOH}-\mathrm{H}_{2} \mathrm{O}(5: 1)$ to give $277 \mathrm{mg} \mathrm{(39 \% )}$ of slightly yellowish crystals $(\mathbf{1 8 c}), \mathrm{mp} 77-79^{\circ} \mathrm{C}$. MS $m / z: 711\left(\mathrm{M}^{+}\right)$. ${ }^{1} \mathrm{H}-\mathrm{NMR}$ $\left(\mathrm{CDCl}_{3}\right) \delta: 2.35\left(3 \mathrm{H}, \mathrm{s}, \mathrm{CCH}_{3}\right), 4.55-4.89\left(3 \mathrm{H}, \mathrm{m}, \mathrm{H}-4^{\prime}, \mathrm{H}-5^{\prime}\right), 5.50(2 \mathrm{H}$, s, $\left.\mathrm{CH}_{2} \mathrm{C}_{6} \mathrm{H}_{5}\right), 6.12-6.40\left(2 \mathrm{H}, \mathrm{m}, \mathrm{H}-2^{\prime}, \mathrm{H}-3^{\prime}\right), 6.80\left(1 \mathrm{H}, \mathrm{s}, \mathrm{H}-1^{\prime}\right), 7.15$ $7.66,7.80-8.30\left(20 \mathrm{H}, \mathrm{m}, \mathrm{C}_{6} \mathrm{H}_{5} \times 4\right), 8.22(1 \mathrm{H}, \mathrm{d}, \mathrm{H}-5, J=2.4 \mathrm{~Hz}), 8.44$ $\left(1 \mathrm{H}, \mathrm{d}, \mathrm{H}-7, J=2.4 \mathrm{~Hz}\right.$ ). Anal. Calcd for $\mathrm{C}_{41} \mathrm{H}_{33} \mathrm{~N}_{3} \mathrm{O}_{9}: \mathrm{C}, 69.19 ; \mathrm{H}, 4.67$; $\mathrm{N}, 5.90$. Found: $\mathrm{C}, 69.02 ; \mathrm{H}, 4.80 ; \mathrm{N}, 5.68$.

1-Benzyl-5-methy]-3-(2',3',5'-tri- $O$-benzoyl- $\beta$-D-ribofuranosyl)pyrido[2,3- $d$ ]pyrimidine-2,4(1H,3H)-dione (18d) According to the general procedure, the crude product was obtained from $15 \mathbf{d}(715 \mathrm{mg}, 1 \mathrm{mmol})$, and recrystallized from $\mathrm{MeOH}-\mathrm{H}_{2} \mathrm{O}(5: 1)$ to give $448 \mathrm{mg}(63 \%)$ of slightly yellowish crystals $(17 \mathrm{~d}), \mathrm{mp} 76-78^{\circ} \mathrm{C}$. MS $\mathrm{m} / \mathrm{z}: 711\left(\mathrm{M}^{+}\right) .{ }^{1} \mathrm{H}-\mathrm{NMR}$ $\left(\mathrm{CDCl}_{3}\right) \delta: 2.77\left(3 \mathrm{H}, \mathrm{s}, \mathrm{CCH}_{3}\right), 4.52-4.83\left(3 \mathrm{H}, \mathrm{m}, \mathrm{H}^{-} 4^{\prime}, \mathrm{H}-5^{\prime}\right), 5.53(2 \mathrm{H}$, $\left.\mathrm{s}, \mathrm{CH}_{2} \mathrm{C}_{6} \mathrm{H}_{5}\right), 6.13-6.42\left(2 \mathrm{H}, \mathrm{m}, \mathrm{H}-2^{\prime}, \mathrm{H}-3^{\prime}\right), 6.77\left(1 \mathrm{H}, \mathrm{s}, \mathrm{H}-1^{\prime}\right), 6.94(1 \mathrm{H}$, d, $\mathrm{H}-6, J=4.8 \mathrm{~Hz}), 7.10-7.65,7.80-8.20\left(20 \mathrm{H}, \mathrm{m}, \mathrm{C}_{6} \mathrm{H}_{5} \times 4\right), 8.42(1 \mathrm{H}$ d, $\mathrm{H}-7, J=4.8 \mathrm{~Hz}$ ). Anal. Calcd for $\mathrm{C}_{41} \mathrm{H}_{33} \mathrm{~N}_{3} \mathrm{O}_{9}: \mathrm{C}, 69.19 ; \mathrm{H}, 4.67 ; \mathrm{N}$, 5.90. Found: C, $69.19 ; \mathrm{H}, 4.86 ; \mathrm{N}, 5.70$.

1-Benzyl-5, 7-dimethyl-3-(2', 3', 5'-tri- $O$-benzoyl- $\beta$-D-ribofuranosyl)pyrrolo[2,3-d $]$ pyrimidine-2,4(1H,3H)-dione (20) A mixture of $\mathrm{PdCl}_{2}$
(177 $\mathrm{mg}, 1 \mathrm{mmol})$ and $17(715 \mathrm{mg}, 1 \mathrm{mmol})$ in dioxane $(20 \mathrm{ml})$ and $\mathrm{H}_{2} \mathrm{O}$ $(2 \mathrm{ml})$ was refluxed for $3 \mathrm{~h}$, then the reaction mixture was evaporated in vacuo. The residue was dissolved in $\mathrm{CHCl}_{3}$ and the solution was applied to the top of a funnel $(4 \mathrm{~cm}$ diameter $\times 6)$ containing silica gel, which was washed with $\mathrm{CHCl}_{3}$. The $\mathrm{CHCl}_{3}$ eluate was evaporated in vacuo, and the residue was purified by crystallization from $\mathrm{MeOH}-\mathrm{H}_{2} \mathrm{O}(5: 1)$ to give $414 \mathrm{mg}(58 \%)$ of pale red crystals $(\mathbf{2 0}), \mathrm{mp} 75-77^{\circ} \mathrm{C}$. MS $m / z: 713\left(\mathrm{M}^{+}\right)$ ${ }^{1} \mathrm{H}-\mathrm{NMR}\left(\mathrm{CDCl}_{3}\right) \delta: 2.62\left(3 \mathrm{H}, \mathrm{s}, \mathrm{CCH}_{3}\right), 3.50\left(3 \mathrm{H}, \mathrm{s}, \mathrm{NCH}_{3}\right), 4.51-4.84$ $\left(3 \mathrm{H}, \mathrm{m}, \mathrm{H}-4^{\prime}, \mathrm{H}-5^{\prime}\right), 5.05\left(2 \mathrm{H}, \mathrm{s}, \mathrm{CH}_{2} \mathrm{C}_{6} \mathrm{H}_{5}\right), 6.25(1 \mathrm{H}, \mathrm{s}, \mathrm{H}-6), 5.97-6.49$ $\left(2 \mathrm{H}, \mathrm{m}, \mathrm{H}-2^{\prime}, \mathrm{H}-3^{\prime}\right), 6.68\left(1 \mathrm{H}, \mathrm{s}, \mathrm{H}-1^{\prime}\right), 7.13-7.64,7.82-8.20(20 \mathrm{H}, \mathrm{m}$ $\left.\mathrm{C}_{6} \mathrm{H}_{5} \times 4\right)$. Anal. Calcd for $\mathrm{C}_{41} \mathrm{H}_{35} \mathrm{~N}_{3} \mathrm{O}_{9}: \mathrm{C}, 68.99 ; \mathrm{H}, 4.94 ; \mathrm{N}, 5.88$. Found: C, $68.90 ; \mathrm{H}, 5.21 ; \mathrm{N}, 5.71$

General Procedure for the Debenzoylation of $18(\mathrm{a}-\mathrm{d})$ and $20 \mathrm{~A}$ solution of 18a-d or $20(1 \mathrm{mmol})$ in anhydrous $\mathrm{MeOH}(12 \mathrm{ml})$ was treated with $1 \mathrm{~N} \mathrm{NaOMe}$ in $\mathrm{MeOH}(0.23 \mathrm{ml})$ and then heated at $50-60^{\circ} \mathrm{C}$ for $2.5 \mathrm{~h}$. The reaction mixture was concentrated in vacuo, then the residue was washed with two portions of hexane $(20 \mathrm{ml} \times 2)$, and dissolved in $\mathrm{CHCl}_{3}$ $\mathrm{MeOH}(7: 3,30 \mathrm{ml})$. This solution was applied to the top of a funnel $(4 \mathrm{~cm}$ diameter $\times 6$ ) containing silica gel, which was washed with $\mathrm{CHCl}_{3}-\mathrm{MeOH}$ $(7: 3)$. The eluate was evaporated in vacuo to get the oil.

1-Benzyl-3-( $\beta$-D-ribofuranosyl)pyrido[2,3-d $]$ pyrimidine-2,4(1 H,3H)dione (19a) According to the general procedure, the product (19a) was obtained from 18a $(697 \mathrm{mg}, 1 \mathrm{mmol})$ in the yield of $339 \mathrm{mg}(88 \%)$ as a slightly yellowish oil. ${ }^{1} \mathrm{H}-\mathrm{NMR}$ [DMSO- $d_{6}$ (added $\left.\left.\mathrm{D}_{2} \mathrm{O}\right)\right] \quad \delta: 3.30-3.90$ $\left(3 \mathrm{H}, \mathrm{m}, \mathrm{H}-4^{\prime}, \mathrm{H}-5^{\prime}\right), 4.21\left(1 \mathrm{H}, \mathrm{t}, \mathrm{H}-3^{\prime}, J=6.0 \mathrm{~Hz}\right), 4.53\left(1 \mathrm{H}, \mathrm{dd}, \mathrm{H}-2^{\prime}, J=\right.$ $6.0,3.3 \mathrm{~Hz}), 5.46\left(2 \mathrm{H}, \mathrm{s}, \mathrm{CH}_{2} \mathrm{C}_{6} \mathrm{H}_{5}\right), 6.23\left(1 \mathrm{H}, \mathrm{d}, \mathrm{H}-1^{\prime}, J=3.3 \mathrm{~Hz}\right), 7.23$ $(1 \mathrm{H}, \mathrm{dd}, \mathrm{H}-6, J=7.8,4.3 \mathrm{~Hz}), 7.15-7.60\left(5 \mathrm{H}, \mathrm{m}, \mathrm{CH}_{2} \mathrm{C}_{6} \underline{\mathrm{H}}_{5}\right), 8.47(1 \mathrm{H}, \mathrm{dd}$, $\mathrm{H}-5, J=7.8,1.9 \mathrm{~Hz}), 8.72(1 \mathrm{H}, \mathrm{dd}, \mathrm{H}-7, J=4.3,1.9 \mathrm{~Hz})$. High MS: Calcd for $\mathrm{C}_{19} \mathrm{H}_{19} \mathrm{~N}_{3} \mathrm{O}_{6}$ (Mol. weight 385.127), Found: $385.128\left(\mathrm{M}^{+}\right.$).

1-Benzyl-7-methyl-3-( $\beta$-D-ribofuranosyl)pyrid o[2,3- $d$ ]pyrimidine2,4(1H,3H)-dione (19b) According to the general procedure, the product (19b) was obtained from $18 \mathrm{~b}(711 \mathrm{mg}, 1 \mathrm{mmol})$ in the yield of $339 \mathrm{mg}(85 \%)$ as a slightly yellowish oil. ${ }^{1} \mathrm{H}-\mathrm{NMR}$ [DMSO- $d_{6}\left(\right.$ added $\left.\left.\mathrm{D}_{2} \mathrm{O}\right)\right] \delta: 2.58(3 \mathrm{H}$, s, $\left.\mathrm{CCH}_{3}\right), 3.40-3.90\left(3 \mathrm{H}, \mathrm{m}, \mathrm{H}-4^{\prime}, \mathrm{H}-5^{\prime}\right), 4.23\left(1 \mathrm{H}, \mathrm{t}, \mathrm{H}-3^{\prime}, J=6.0 \mathrm{~Hz}\right)$, $4.57\left(1 \mathrm{H}, \mathrm{dd}, \mathrm{H}-2^{\prime}, J=6.0,3.3 \mathrm{~Hz}\right), 5.46\left(2 \mathrm{H}, \mathrm{s}, \mathrm{CH}_{2} \mathrm{C}_{6} \mathrm{H}_{5}\right), 6.26(1 \mathrm{H}, \mathrm{d}, \mathrm{H}-$ $\left.1^{\prime}, J=3.3 \mathrm{~Hz}\right), 7.10(1 \mathrm{H}, \mathrm{d}, \mathrm{H}-6, \quad J=7.8 \mathrm{~Hz}), 7.02-7.60(5 \mathrm{H}, \mathrm{m}$, $\left.\mathrm{CH}_{2} \mathrm{C}_{6} \underline{\mathrm{H}}_{5}\right), 8.39(1 \mathrm{H}, \mathrm{d}, \mathrm{H}-5, J=7.8 \mathrm{~Hz})$. High MS: Calcd for $\mathrm{C}_{20} \mathrm{H}_{21} \mathrm{~N}_{3} \mathrm{O}_{6}$ (Mol. weight 399.143), Found: $399.144\left(\mathrm{M}^{+}\right)$

1-Benzyl-6-methyl-3-( $\beta$-D-ribofuranosyl)pyrido $[2,3-d]$ pyrimidine$2,4(1 \mathrm{H}, 3 \mathrm{H})$-dione $(19 \mathrm{c})$ According to the general procedure, the product (19c) was obtained from $18 \mathrm{c}(711 \mathrm{mg}, 1 \mathrm{mmol})$ in the yield of $259 \mathrm{mg}(65 \%)$ as a slightly yellowish oil. ${ }^{1} \mathrm{H}-\mathrm{NMR}$ [DMSO- $d_{6}\left(\right.$ added $\left.\left.\mathrm{D}_{2} \mathrm{O}\right)\right] \delta: 2.37(3 \mathrm{H}$, s. $\left.\mathrm{CCH}_{3}\right), 3.35-3.90\left(3 \mathrm{H}, \mathrm{m}, \mathrm{H}-4^{\prime}, \mathrm{H}-5^{\prime}\right), 4.16\left(1 \mathrm{H}, \mathrm{t}, \mathrm{H}-3^{\prime}, J=6.0 \mathrm{~Hz}\right)$, $4.53\left(1 \mathrm{H}, \mathrm{dd}, \mathrm{H}-2^{\prime}, J=6.0,3.6 \mathrm{~Hz}\right), 5.43\left(2 \mathrm{H}, \mathrm{s}, \mathrm{CH}_{2} \mathrm{C}_{6} \mathrm{H}_{5}\right), 6.22(1 \mathrm{H}, \mathrm{d}, \mathrm{H}-$ $\left.\mathrm{l}^{\prime}, J=3.6 \mathrm{~Hz}\right), 7.20-7.60\left(5 \mathrm{H}, \mathrm{m}, \mathrm{CH}_{2} \mathrm{C}_{6} \mathrm{H}_{5}\right), 8.26(1 \mathrm{H}, \mathrm{d}, \mathrm{H}-5, J=$ $2.1 \mathrm{~Hz}), 8.52(1 \mathrm{H}, \mathrm{d}, \mathrm{H}-7, J=2.1 \mathrm{~Hz})$. High MS: Calcd for $\mathrm{C}_{20} \mathrm{H}_{21} \mathrm{~N}_{3} \mathrm{O}_{6}$ (Mol. weight 399.143), Found: $399.144\left(\mathrm{M}^{+}\right)$

1-Benzyl-5-methyl-3-( $\beta$-D-ribofuranosyl)pyrido $[2,3-d]$ pyrimidine$2,4(1 H, 3 H)$-dione $(19 d)$ According to the general procedure, the product (19d) was obtained from $18 \mathrm{~d}(711 \mathrm{mg}, 1 \mathrm{mmol})$ in the yield of $338 \mathrm{mg}(85 \%)$ as a slightly yellowish oil. ${ }^{1} \mathrm{H}-\mathrm{NMR}$ [DMSO- $d_{6}$ (added $\left.\left.\mathrm{D}_{2} \mathrm{O}\right)\right] \delta: 2.75(3 \mathrm{H}$, s, $\left.\mathrm{CCH}_{3}\right), 3.20-3.91\left(3 \mathrm{H}, \mathrm{m}, \mathrm{H}-4^{\prime}, \mathrm{H}-5^{\prime}\right), 4.23\left(1 \mathrm{H}, \mathrm{t}, \mathrm{H}-3^{\prime}, J=6.0 \mathrm{~Hz}\right)$, $4.48\left(1 \mathrm{H}, \mathrm{dd}, \mathrm{H}-2^{\prime}, J=6.0,3.3 \mathrm{~Hz}\right), 5.49\left(2 \mathrm{H}, \mathrm{s}, \mathrm{CH}_{2} \mathrm{C}_{6} \mathrm{H}_{5}\right), 6.24(1 \mathrm{H}, \mathrm{d}, \mathrm{H}-$ $\left.1^{\prime}, J=3.3 \mathrm{~Hz}\right), 7.06(1 \mathrm{H}, \mathrm{d}, \mathrm{H}-6, J=5.4 \mathrm{~Hz}), 7.01-7.49(5 \mathrm{H}, \mathrm{m}$, $\left.\mathrm{CH}_{2} \mathrm{C}_{6} \mathrm{H}_{5}\right), 8.44(1 \mathrm{H}, \mathrm{d}, \mathrm{H}-7, J=5.4 \mathrm{~Hz})$. High MS: Calcd for $\mathrm{C}_{20} \mathrm{H}_{21} \mathrm{~N}_{3} \mathrm{O}_{6}$ (Mol. weight 399.143), Found: $399.143\left(\mathrm{M}^{+}\right)$.

1-Benzyl-5,7-dimethyl-3-( $\beta$-D-ribofuranosyl)pyrrolo $[2,3-d]$ pyrimidine2,4(1 $\mathrm{H}, 3 \mathrm{H})$-dione (21) According to the general procedure, the product (21) was obtained from $20(713 \mathrm{mg}, 1 \mathrm{mmol})$ in the yield of $337 \mathrm{mg}(84 \%)$ as a brownish oil. ' $\mathrm{H}-\mathrm{NMR}$ [DMSO- $d_{6}$ (added $\left.\left.\mathrm{D}_{2} \mathrm{O}\right)\right] \delta: 2.62(3 \mathrm{H}$, s, $\left.\mathrm{CCH}_{3}\right), 3.47\left(3 \mathrm{H}, \mathrm{s}, \mathrm{NCH}_{3}\right), 3.33-3.85\left(3 \mathrm{H}, \mathrm{m}, \mathrm{H}-4^{\prime}, \mathrm{H}-5^{\prime}\right), 4.07(1 \mathrm{H}, \mathrm{t}$, $\left.\mathrm{H}-3^{\prime}, J=6.0 \mathrm{~Hz}\right), 4.40\left(1 \mathrm{H}, \mathrm{dd}, \mathrm{H}-2^{\prime}, J=6.0,3.3 \mathrm{~Hz}\right), 4.99(2 \mathrm{H}, \mathrm{s}$, $\left.\mathrm{C}_{2} \mathrm{C}_{6} \mathrm{H}_{5}\right), 6.05\left(1 \mathrm{H}, \mathrm{d}, \mathrm{H}-1^{\prime}, J=3.3 \mathrm{~Hz}\right), 6.34(1 \mathrm{H}, \mathrm{s}, \mathrm{H}-6), 6.97-7.44$ $\left(5 \mathrm{H}, \mathrm{m}, \mathrm{CH}_{2} \mathrm{C}_{6} \mathrm{H}_{5}\right.$ ). High MS: Calcd for $\mathrm{C}_{20} \mathrm{H}_{23} \mathrm{~N}_{3} \mathrm{O}_{6}$ (Mol. weight 401.159), Found: $401.158\left(\mathrm{M}^{+}\right)$.

Acknowledgement We are grateful to Mrs. A. Nakatani, Miss A. Nakagawa, Mrs. C. Sakabe, and Mrs. N. Satoh, School of Pharmaceutical Sciences, Kitasato University, for microanalyses and spectral measurements. This work was supported in part by Grants-in-Aid for Cancer Research (No. 61010096, No. 62010033 and No. 63010031) from the Ministry of Education, Science and Culture, Japan.

References and Notes

1) On leave from the Department of Heterocyclic Chemistry, Mnjoyan 
Institute of Fine Organic Chemistry, Academy of Sciences of Arm. SSR, 1986-1987.

2) T. Itoh, T. Imini, H. Ogura, N. Kawahara, T. Nakajima, and K. A. Watanabe, Chem. Pharm. Bull., 33, 1375 (1985).

3) a) B. H. Rizkalla and A. D. Broom, J. Org. Chem., 37, 3980 (1972); b) G. L. Anderson and A. D. Broom, ibid, 42, 997 (1977).

4) T.-L. Su, K. Harada, and K. A. Watanabe, Nucleosides \& Nucleotides, 3, 513 (1984).

5) a) J. A. Cavins, Proc. Amer. Ass. Cancer Res., 7, 12 (1966); b) K. V. Rao and D. W. Renn, Antimicrob. Agents Chemother., 1963, 77.

6) a) H. Nishimura, K. Katagiri, K. Sato, N. Mayama, and N Shimaoka, J. Antibiot., 9, 60 (1956); b) R. L. Tolman, R. K. Robins, and L. B. Townsend, J. Am. Chem. Soc., 90, 524 (1968).

7) a) K. Anzai, G. Nakamura, and S. Suzuki, J. Antibiot., 10, 201 (1957); b) S. Suzuki and S. Marumo, ibid., 13, 360 (1960).

8) We will report the procedure and elucidation of compound $\mathbf{8}$ in another journal in the near future.

9) U. Niedballa and H. Vorbrüggen, J. Org. Chem., 41, 2084 (1976).

10) Data on inhibition of cell proliferation and induction of differentiation of human myeloid leukemia cells by some typical products are given in Table I.
TABLE I. Effect of Some Typical Products on Growth and Differentiation of HL-60 Cells

\begin{tabular}{ccc|ccc}
\hline Compd. & $\begin{array}{c}\mathrm{GD}_{50} \\
(\mu \mathrm{g} / \mathrm{ml})^{a)}\end{array}$ & $\begin{array}{c}\text { NBT reduction } \\
(\%)^{b)}\end{array}$ & Compd. & $\begin{array}{c}\mathrm{GD}_{50} \\
(\mu \mathrm{g} / \mathrm{ml})^{a)}\end{array}$ & $\begin{array}{c}\text { NBT reduction } \\
(\%)^{b)}\end{array}$ \\
\hline $\mathbf{1 5 a}$ & 25 & \pm & $\mathbf{1 9 a}$ & 65 & ++ \\
$\mathbf{1 5 b}$ & 110 & + & $\mathbf{1 9 b}$ & 58 & ++ \\
$\mathbf{1 5 c}$ & 25 & ++ & $\mathbf{1 9 c}$ & 55 & +++ \\
$\mathbf{1 5 d}$ & 65 & - & $\mathbf{1 9 d}$ & 23 & +++ \\
$\mathbf{1 6}$ & 45 & - & $\mathbf{2 1}$ & 60 & + \\
$\mathbf{1 7}$ & 145 & \pm & & & + \\
\hline
\end{tabular}

Symbols: $--10 \% \pm 10-30 \%+30-60 \%+++>80 \%$ a) $\mathrm{GD}_{50}$, con centration resulting in half the number of control generations. b) HL-60 cells were cultured with the $\mathrm{GD}_{50}$ concentration of each compound for $6 \mathrm{~d}$.

Cells and cells culture. Human promyelocytic leukemia HL-60 cells were maintained in RPMI-1640 medium supplemented with $10 \%$ fetal calf serum. ${ }^{11}$

Assay of properties of differentiated cells. Nitroblue tetrazolium reduction was assayed. ${ }^{11}$ ) The percentage of cells containing intracellular blue-black formazan deposits was then determined by examination of at least 300 cells. The percentages of cells that were morphologically similar to mature granulocytes were determined in smears treated with May-Gruenwald-Giemsa stain.

11) S. J. Collins, A. H. Bodner, R. Ting and R. C. Gallo, Int. J. Cancer, 25, $213(1980)$ 